Chimia 46 (1992) 323-334

(C) Neue Schweizerische Chemische Gesellschaft ISSN 0009-4293

\title{
Isosterism and Bioisosterism Case Studies with Muscarinic Agonists
}

\author{
Philipp Floersheim*, Esteban Pombo-Villar*, and Gideon Shapiro*
}

Abstract. The synthesis and activity of enantiomerically pure analogues of pilocarpine and muscarinic agonists with the azabicyclo[2.2.1] heptane skeleton is described. Structure-activity relationships support a flexible model in which a coulombic interaction as well as two $\mathrm{H}$-bonding interactions with the receptor are necessary for potent muscarinic agonist activity. In this context, a critical appraisal of the concepts of isosterism and bioisosterism is put forward, isosterism is redefined, and bioisosterism is discarded in favor of the new concept of bioanalogy.

\section{Introduction}

The past decade has witnessed considerable interest of the medicinal chemist in muscarinic agonists. One of the principal reasons for this is the therapeutic potential of a centrally active muscarinic agonist in Alzheimer's Disease (AD) [1]. The cholinergic hypothesis of $A D$ maintains that the acetylcholine deficit characteristic of the disease directly contributes to the symptomatic cognitive deficiency in these patients [2]. As a corollary, improvement of cholinergic function or neurotransmission should be of therapeutic value for $A D$ patients. Direct stimulation of the cholinergic system with a centrally active muscarinic agonist is one approach toward achieving this end [3]. Acetylcholine receptors were classified by Dale early this century [4] in two fundamental subtypes, nicotinic and muscarinic. More recently, the muscarinic receptors themselves have been subclassified. To date, three pharmacologically distinct subtypes (M1, M2, and M3) are accepted [5], while five molecular subtypes ( $\mathrm{ml}-\mathrm{m} 5)$ have been found by receptor cloning [6]. There is great structural diversity among muscarinic agonists, and yet the structural and geomet-

*Correspondence to any of the three authors: Dr. E. Pombo-Villar, Dr. G. Shapiro Preclinical Research, Sandoz Pharma Ltd. CH-4002 Basel

Dr. P. Floersheim

Drug Design Group, Sandoz Pharma Ltd. CH-4002 Basel rical requirements are very stringent [7].

Bioisosterism is an important concept [8] which serves as a valuable aid to the medicinal chemist in exploring structureactivity relationships (SAR) and designing new drugs by analogy with known compounds. In turn, the term bioisosterism has a certain vagueness, and by overextending its scope, rational structural understanding can drift to the background or worse, be completely lost. The following study of isosterism and bioisosterism in analogues of three structurally distinct muscarinic agonists: pilocarpine, (5methylfurfuryl)trimethylammonium iodide (5-MFT), and azabicycloheptanes (see 1) is illustrative of the scope and limitations of these concepts.

\subsection{Pilocarpine and MFT Analogs}

Recently, an SAR study of pilocarpine analogs in which the lactone structural element of $(+)$-pilocarpine was modified has been reported from our laboratories [9]. In this report, a hypothetical model for the binding of muscarinic agonists to the $\mathrm{m} 1$ receptor subtype was also proposed. The muscarinic agonist activity found for the analogues thiolactone $2[10]$, lactam 3 , dithiolactone 4 , tetrahydrofuran 5 , and lactol 6 indicated that of the two pilocarpine lactone oxygens, the carbonyl oxygen is of primary importance for muscarinic agonist activity while the ether oxygen assumes a secondary role. The cisconfiguration of the Et-group at C(3) and the imidazomethyl group at $\mathrm{C}(4)$ of pilocarpine is essential for maintaining muscarinic agonist activity [10]. Isopilocarpine, the trans- isomer having the inverted configuration at $C(3)$, is much less active. Furthermore, the center at $\mathrm{C}(3)$ of pilocarpine is prone to epimerization posing a problem in preparing analogs in which this is also the case. Dithiolactone 4 epimerizes spontaneously and only the trans-diastereoisomer could be isolated. Thionolactone 7 , in which only the carbonyl oxygen is replaced with sulfur, could not be isolated, but here as well epimerization would presumably have been a serious problem. The discovery of the oxazolidinone 8 [11] which, as a muscarinic agonist, is virtually equiactive to pilocarpine has greatly expanded the range of accessible pilocarpine analogs. The problem of stereochemical lability at C(3) for pilocarpine is obviated in the case of the oxazolidinone 8 . This enantiomerically pure compound is derived from L-histidine and has absolute configuration analogous to that of pilocarpine but has a trigonal $\mathrm{N}$-atom in place of the chiral center at C(3). Moreover, in the case of 8 , exchange of either or both $\mathrm{O}$-atoms for $\mathrm{S}$ -

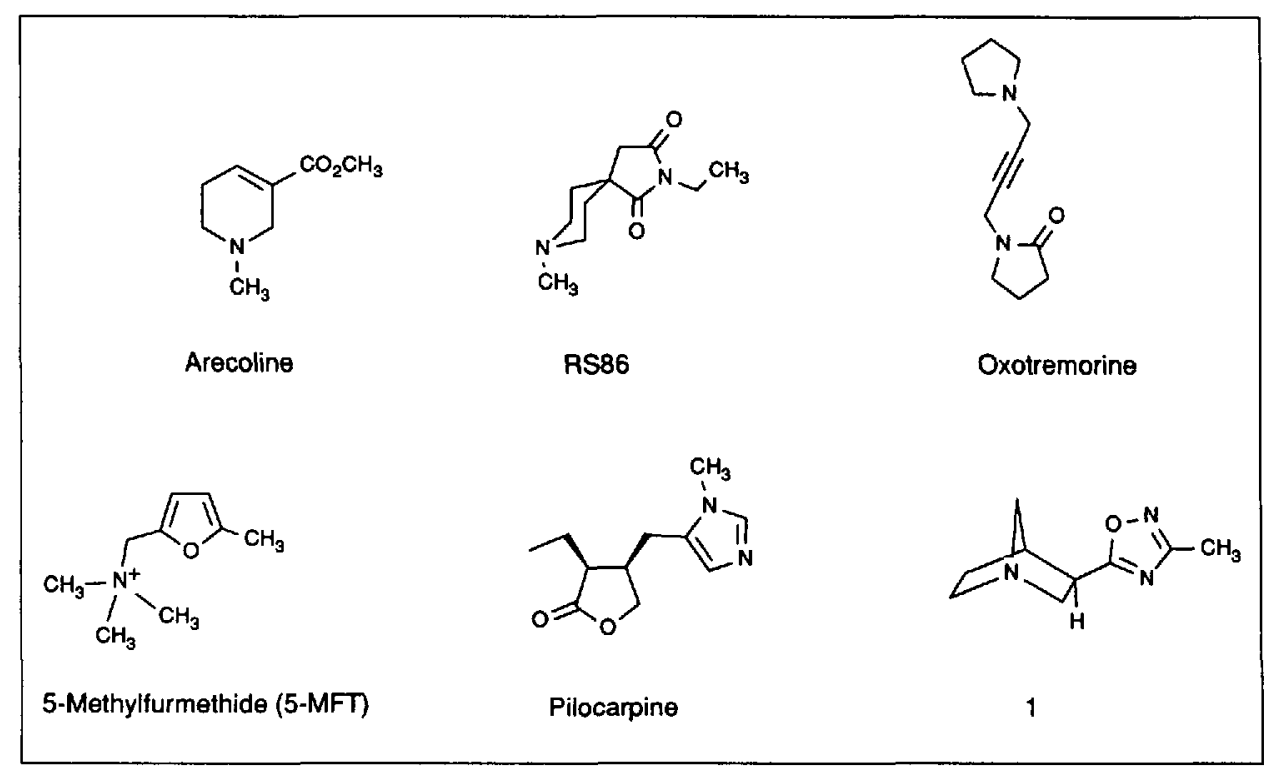



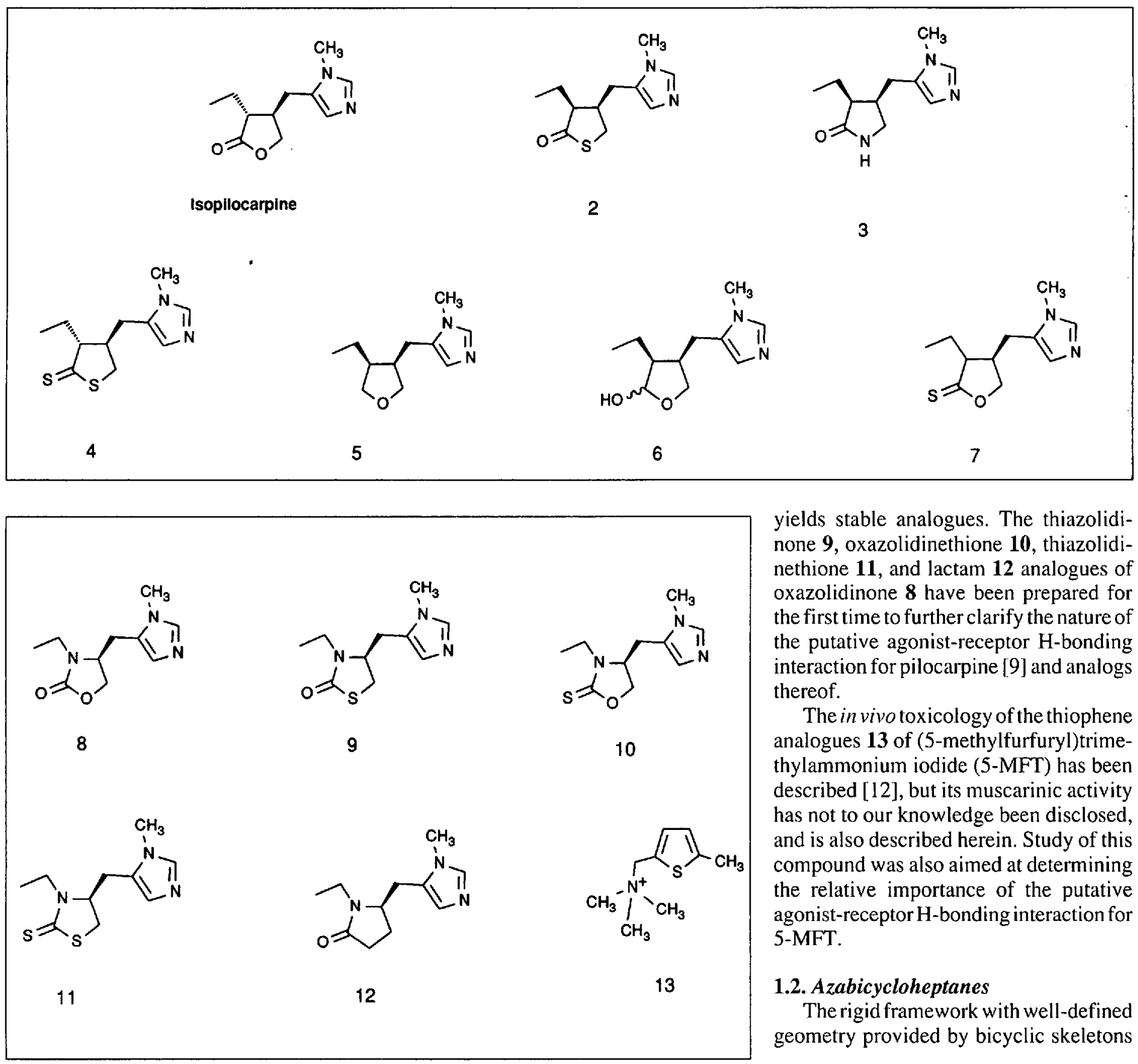

yields stable analogues. The thiazolidinone 9 , oxazolidinethione 10 , thiazolidinethione 11, and lactam 12 analogues of oxazolidinone 8 have been prepared for the first time to further clarify the nature of the putative agonist-receptor $\mathrm{H}$-bonding interaction for pilocarpine [9] and analogs thereof.

The in vivo toxicology of the thiophene analogues 13 of (5-methylfurfuryl)trimethylammonium iodide (5-MFT) has been described [12], but its muscarinic activity has not to our knowledge been disclosed, and is also described herein. Study of this compound was also aimed at determining the relative importance of the putative agonist-receptor $\mathrm{H}$-bonding interaction for 5-MFT.

\subsection{Azabicycloheptanes}

The rigid framework with well-defined geometry provided by bicyclic skeletons<smiles>Cc1noc(C2CN3CCCC2(C)C3)n1</smiles>

$(-)-1 \cdot 4$<smiles>[R]C1CC2C[NH+]([R])CC1([R])C2OC(C)=O</smiles>

(+)-27 R=H (+)-28 R= $=\mathrm{CH}_{3}$<smiles>[R]C1C2CC(c3nc(C)no3)C([R])C1N([R])C2</smiles>

$(-)-37 \mathrm{R}=\mathrm{H}$

$(-)-38 \mathrm{R}=\mathrm{CH}_{3}$<smiles>Nc1noc(C2CC3CCC2C3)n1</smiles>

40<smiles>[R]C1C2C=CN(SC)C1C(OC(C)=O)CS2</smiles>

(-) -41<smiles>CC1CN2CCC1CC2c1nc(N)no1</smiles>

$(-)-42$<smiles>Cc1nsc(C2CN3CCC2CC3)n1</smiles> 
has been widely exploited in medicinal chemistry. Rigid analogues of biogenic amines can display large increases in potency relative to their more flexible congeners due to a lower negative entropy of binding to the receptor. They can also exhibit increased selectivity, by restricting the conformational space and the volume available for interaction with particular receptors.

We have previously reported the preparation of the enantiomerically pure acetates (+)-41 and (-)-41 derived from 1azabicyclo[2.2.1] heptan-3-ol [13]. Here, we report for the first time their biological activities and compare them with the corresponding analogues 1 and 42 in which the acetate is replaced with a 3-methyland 3-amino-substituted 1,2,4-oxadiazole ring, respectively. These compounds which, to our knowledge, are the most potent muscarinic agonists known to date, were first described as racemic mixtures [14a], but have since been described in enantiomerically pure form [14c][15].

In an analogous series, the novel 6substituted 2-azabicyclo[2.2.1]heptanes $27,28,37$, and 38 have been prepared, and their muscarinic activity is described. The biological activity of these two series of compounds provides insight into the properties of 1,2,4-oxadiazoles as analogues of an acetate moiety.

The carbocyclic compound norbornane oxadiazole $\mathbf{4 0}$ is closely analogous to the potent muscarinic agonist azabicycloheptane 42, but cannot assume a positive charge. This compound serves as a probe for the relative importance of the putative ionic bonding interaction of muscarinic agonists to the receptor.

\section{Pharmacology}

The use of selective antagonists has demonstrated the existence of three pharmacologically [16] distinct subtypes of muscarinic receptors. These subtypes denoted M1, M2, and M3 have different cellular locations and mediate varied physiological responses. Generally speaking, M1 receptors are located on neurons, M2 receptors are located in cardiac tissue and have been shown to be responsible for the modulation of central Ach release [17], and $\mathrm{M} 3$ receptors are located on smooth muscles and glands. In our laboratories, the slow depolarization of the rat cervical ganglion and the rat hippocampal slice firing rate serve as different functional $\mathrm{M} 1$ models [9] and the guinea-pig ileum contraction [18] as a functional M3 model [19]. The affinity of all compounds to muscarinic receptors was determined by their abitity to displace $\left[{ }^{3} \mathrm{H}\right]$ pirenzepine

Scheme 1

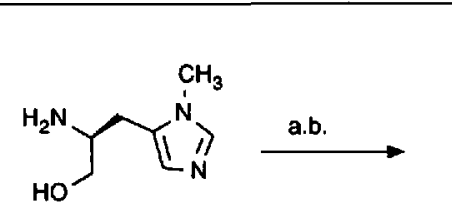

14

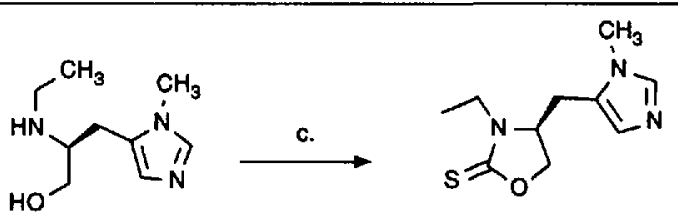

10

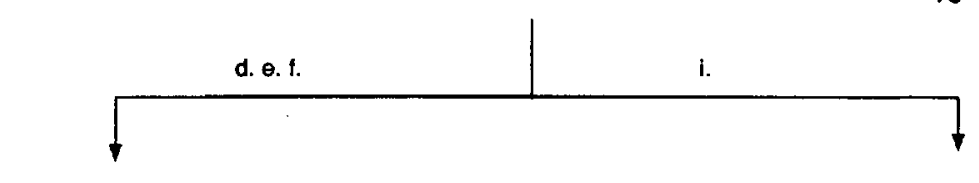<smiles>CCN(C(=O)OC(C)(C)C)[C@H](CS)Cc1cncn1C</smiles>

16<smiles>CCN[C@@H](CS)Cc1cncn1C</smiles>

17<smiles>CCN1C[C@H]1Cc1cncn1C</smiles>

18<smiles>CCN1C(=S)SC[C@@H]1Cc1cncn1C</smiles>

11

n.<smiles>CCN1C(=O)SC[C@H]1Cc1cncn1C</smiles>

9

a) 2 equiv. $\mathrm{Ac}_{2} \mathrm{O}, \mathrm{CH}_{2} \mathrm{Cl}_{2}, 1$ h, $0^{\circ}, 1$ h, r.t., 75\%; b) 6 equiv. $\mathrm{LiAlH}_{4}$, THF, 1 h, r.t., 3 h reflux, $84 \%$; c) thiocarbonyldiimidazole, $\mathrm{CH}_{2} \mathrm{Cl}_{2},-15^{\circ}, 18 \mathrm{~h}, 65 \%$; d) 2 equiv. $\mathrm{Boc}_{2} \mathrm{O}, \mathrm{Et}_{3} \mathrm{~N}, \mathrm{CH}_{2} \mathrm{Cl}_{2}, 18 \mathrm{~h} ; \mathrm{K}_{2} \mathrm{CO}_{3}$, $\mathrm{MeOH}, 18 \mathrm{~h}, 65 \%$; e) $\mathrm{CH}_{3} \mathrm{COSH}, \mathrm{DEAD}, \mathrm{Ph}_{3} \mathrm{P}, \mathrm{THF}, 71 \%$; ) $\mathrm{NaOMe}, \mathrm{MeOH}, 1$ h, r.t., 90\%; g) $\mathrm{HSCH}_{2} \mathrm{CH}_{2} \mathrm{SH}, \mathrm{CF}_{3} \mathrm{CO}_{2} \mathrm{H}, \mathrm{THF}, 4 \mathrm{~h}$; h) carbonyldiimidazole, $\mathrm{CH}_{2} \mathrm{Cl}_{2}, 18 \mathrm{~h}, 25 \%$ from 16; i) DEAD, $\mathrm{Ph}_{3} \mathrm{P}, \mathrm{THF}, 80 \%$; j) $\mathrm{CS}_{2}, \mathrm{MeOH}, 72$ h, r.t., $70 \%$

(Pir) and cis- $\left[{ }^{3} \mathrm{H}\right]$ methyl(dimethyl-aminomethyl-1,3-dioxolane) (CD) in rat cortical tissue. Pirenzepine [20] is an antagonist which is selective for the M1 or neuronal subtype of muscarinic receptors and $\mathrm{CD}$ [21] is a nonselective, potent muscarinic agonist. The $\mathrm{CD}$-binding provides a general measure of central muscarinic agonist activity, and the pirenzepine (Pir) binding yields an indication of central muscarinic antagonist activity.

\section{Synthesis [22]}

\subsection{Oxazolidinone Analogs}

The optically pure aminoalcohol 14, an intermediate in the synthesis [11b] of the oxazolidinone (4S)-8 from L-histidine, served as the starting material for the synthesis of the sulfur analogs of $\mathbf{8}$ (Scheme 1). Acetylation of $\mathbf{1 4}$ followed by $\mathrm{LiAlH}_{4}$ reduction gave the $N$-ethyl derivative 15 . Treatment of 15 with thiocarbonyldiimidazole gave the oxazolidinethione (4S)10 which was converted to its corresponding hydrogen fumarate salt [23]. Protection of 15 with di(tert-butyl) dicarbonate $\left(\mathrm{Boc}_{2} \mathrm{O}\right)$ followed by Mitsunobu reaction with thioacetic acid [24] and thioester hydrolysis gave thiol 16. Removal of the Boc group of 16 using $\mathrm{CF}_{3} \mathrm{COOH}$ without scavengers resulted in transfer of the $t$-Bu group to the thiol function. To suppress this internal scavenging reaction it was necessary to add a large amount of ethanedithiol as an external scavenger of $t-\mathrm{Bu}$ cations. Cleavage of the Boc group with $\mathrm{CF}_{3} \mathrm{COOH} /$ ethanedithiol/THF 1.5:1:1 gave aminothiol 17, which was then cyclized with carbonyldiimidazole to the crystalline thiazolidinone ( $4 S)-9$ which was converted to its corresponding fumarate salt [25]. Treatment of 15 with $\mathrm{Ph}_{3} \mathrm{P} /$ dia- 
(c)

a) $\mathrm{AlH}_{3}$, THF, 18 h, r.t., 5 h reflux, 95\%; b) 2 equiv. $\mathrm{Ac}_{2} \mathrm{O}, \mathrm{CH}_{2} \mathrm{Cl}_{2}, 30 \mathrm{~min}, 0^{\circ}, 18$ h, r.t., 97\%; c) $\mathrm{LiAlH}_{4}$, THF, $1 \mathrm{~h}$, r.t., $3 \mathrm{~h}$ reflux, $84 \%$; d) $(\mathrm{COCl})_{2}$, DMSO, (i-Pr) $)_{2} \mathrm{EtN}, \mathrm{CH}_{2} \mathrm{Cl}_{2}, 56 \%$; e) (EtO) ${ }_{2} \mathrm{PCH}_{2} \mathrm{CO}_{2} \mathrm{Et}, \mathrm{LiBr}, \mathrm{Et}_{3} \mathrm{~N}, \mathrm{THF}, 1 \mathrm{~h}, 0^{\circ}, 18$ h, r.t., $70 \%$; $\left.) \mathrm{H}_{2}, 10 \% \mathrm{Pd} / \mathrm{C} \mathrm{AcOH}, \mathrm{MeOH} ; \mathrm{g}\right)(\mathrm{AcO})_{2} \mathrm{O}, \mathrm{MeOH}$, reflux, $85 \%$ from 23 .

Scheme 3. Stereoselective Synthesis of 6-Substituted 2-Azabicyclo[2.2.1] heptanes

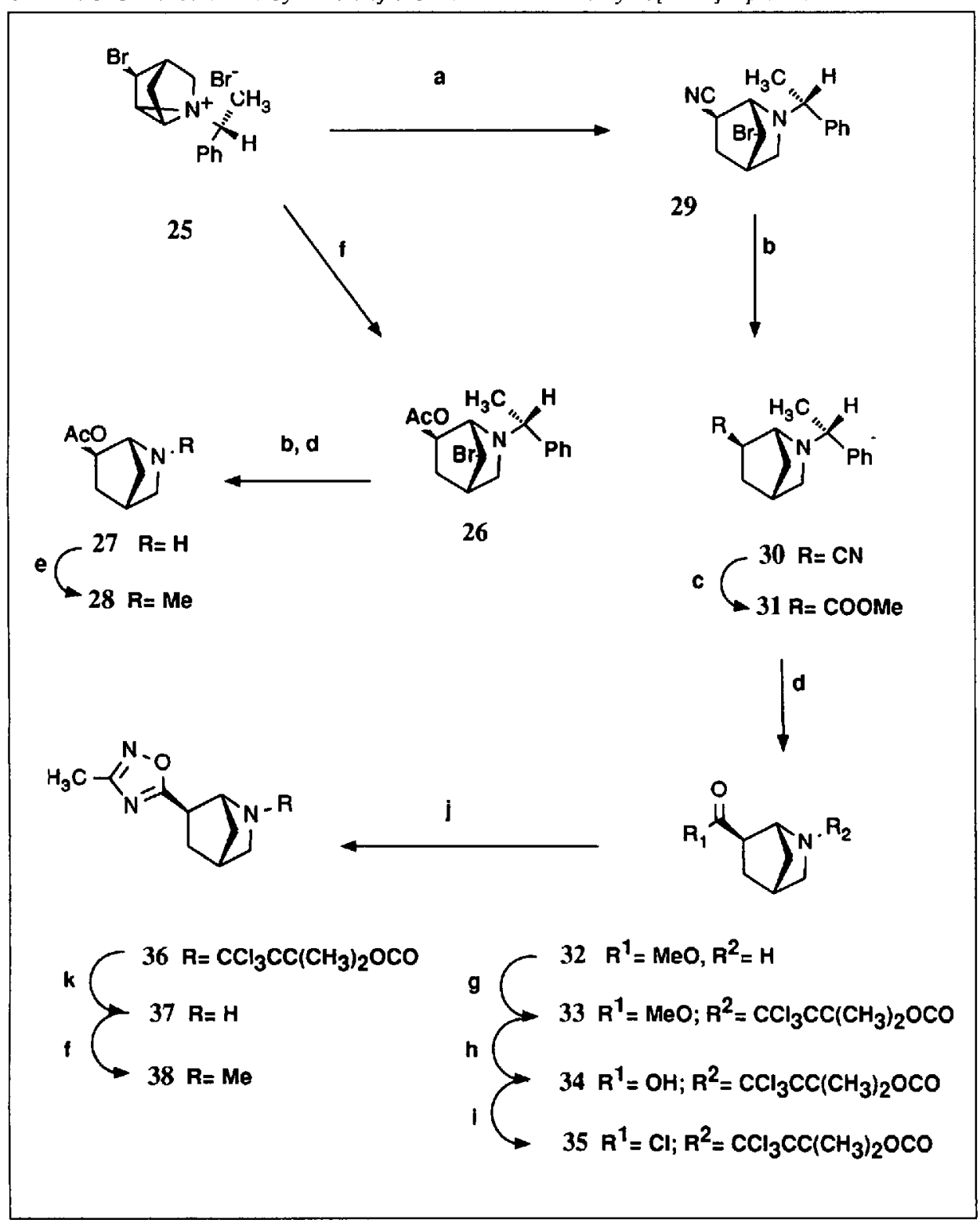

Reagents and conditions: a) $\mathrm{Et}_{4} \mathrm{NCN}, \mathrm{CH}_{2} \mathrm{Cl}_{2}, 65 \%$; b) Bu 3 SnH, AIBN, reflux, $3 \mathrm{~h}, 96 \%$; c) $\mathrm{HCl}$ $\mathrm{MeOH}, 2 \mathrm{~h}$ reflux, $91 \%$; d) $\mathrm{H}_{2}, \mathrm{Pd} / \mathrm{C}, \mathrm{AcOH}, 5 \mathrm{~atm}, 86 \%$; e) $\mathrm{H}_{2} \mathrm{CO}, \mathrm{HCOOH}, 90^{\circ}, 1 \mathrm{~h}, 90 \%$; f) $\mathrm{NaOAc}$, $\left.\mathrm{AcOH}, 70^{\circ}, 3 \mathrm{~h}, 100 \% ; \mathrm{g}\right) \mathrm{Cl}_{3} \mathrm{CC}\left(\mathrm{CH}_{3}\right)_{2} \mathrm{OCOCl}$, i- $\mathrm{Pr}_{2} \mathrm{EtN}, \mathrm{CH}_{2} \mathrm{Cl}_{2}, 18 \mathrm{~h}, 78 \%$; h) $\mathrm{NaOH}, \mathrm{MeOH}, 30$ $\min , 65^{\circ}, 89 \%$; i) $\mathrm{SO}_{2} \mathrm{Cl}_{2}, 100 \%$; j) $\mathrm{CH}_{3} \mathrm{CNH}_{2} \mathrm{NOH}, \mathrm{Py}, 80^{\circ}, 61 \%$; k) $\mathrm{Zn}, \mathrm{AcOH}, 26 \%$. zodiethyldicarboxylate gave aziridine 18 which was converted with $\mathrm{CS}_{2}$ [26] to the crystalline thiazolidinethione free base $(4 S)-11[27]$.

Another intermediate from the synthesis [11b] of (4S)-8, the $N$-benzoyl histidine ester 19, was the starting material for the synthesis of the lactam analogue (4S)12 (Scheme 2). $\mathrm{LiAlH}_{4}$ reduction of 19 gave 20, which was then subjected to acetylation and $\mathrm{LiAlH}_{4}$ reduction to give $N$-benzyl- $N$-ethylamino-alcohol 21. Swern oxidation of 21 to the corresponding aldehyde 22 followed by Wadsworth-Emmons olefination gave enone 23. Catalytic reduction of 23 resulted in double bond reduction with concomitant $N$-debenzylation to give the corresponding amino ester 24. Treatment of 24 with $\mathrm{AcOH}$ in refluxing EtOH gave lactam (4S)-12 which was crystallized as the corresponding $\mathrm{HCl}$ salt [28].

\subsection{2-Azabicycloheptanes}

The homochiral 2-azabicyclo[2.2.1]heptane acetates $(+)-(1 R, 4 S, 6 R)-27$ and (+)-( $1 R, 4 S, 6 R)-28$ were obtained (Scheme $3)$ from the ring-opening reaction of the enantiomerically pure aziridinium bromide (+)-(1S,2S,3S,4S,6S, ' $R)-25$, in analogous fashion to that which we have previously described for the synthesis of analogues of arecoline [29] using the elegant chemistry developed by Grob and Dratva for the racemic series [30]. As expected, reaction of $(+)-25$ with AcONa provided the corresponding enantiomer $\left(1 S, 4 S, 6 R, 7 S, I^{\prime} R\right)$ 26, which was immediately reduced with $\mathrm{Bu}_{3} \mathrm{SnH}$ followed by catalytic hydrogenolysis in $\mathrm{AcOH}$ with $\mathrm{Pd} / \mathrm{C}$, using a Parr medium pressure reactor, resulting after $40 \mathrm{~h}$ reaction in the acetoxy amine (+)-(1R,4S,6R)-27, which was crystallized 
as its hydrogen fumarate salt [31]. The free base (+)-27 was reductively methylated using Eschweiler-Clarke conditions to $(+)-(1 R, 4 S, 6 R)-28$, which was crystallized as its hydrogen fumarate [32].

The methyl ester (-)-(1R,4R,6R)-32 was obtained from $(+)-25$ [29]. Treatment of (+)-25 with triethylammonium cyanide gave the crystalline (+)-( $\left.1 S, 4 R, 6 R, 7 S, 1^{\prime} R\right)$ 29, which was subsequently reduced to $(-)-(1 R, 4 R, 6 R, \mathrm{I} R)-30$. Acid-catalyzed methanolysis to the protected methyl ester $\left(1 R, 4 R, 6 R, 1^{\prime} R\right)-31$, and hydrogenolysis of the chiral auxillary gave $(-)-(1 R, 4 R, 6 R)$ 32 [29].

The corresponding enantiomers were obtained from the enantiomeric aziridinium bromide (-)-25. The absolute configurations of these compounds were established from X-ray crystallographic determination of the structure of $(+)-25$ [33].

With the methyl esters of (+)- and (-)32 available, the corresponding oxadiazoles were synthesized. Thus, from (-)$(1 R, 4 R, 6 R)-32$, by protection of the amine as the crystalline [(1,1-dimethyl-2,2,2trichloroethyl)oxy] carbonyl derivative (-)-33, hydrolysis with methanolic $\mathrm{NaOH}$ to the crystalline free acid (-)-34 was readily performed. This acid was converted to the acid chloride (-)-35 followed by cyclization with acetamidine oxime in pyridine to 36 , which was treated with $\mathrm{Zn}$ / $\mathrm{AcOH}$ to generate the exo-substituted azabicycloheptane (-)-(1R,4R,6R)-37 which was crystallized as a hydrogen fumarate [34]. This amine was subjected to an Eschweiler-Clarke procedure to yield $(-)-(1 R, 4 R, 6 R)-38$, the corresponding $N$ methylated analogue, which was crystallized as a hydrogen maleinate [35]. The corresponding enantiomers were obtained in analogous fashion from $(+)-(1 S, 4 S, 6 S)$ 32. Formation of the oxadiazoles from the acid chlorides was cleaner than directly from the esters, and did not result in epimerization at $\mathrm{C}(6)$.

\subsection{1-Azabicycloheptanes}

We have previously reported the synthesis of enantiomerically pure 1-azabicyclo[2.2.1] hept-3-yl acetates 41, from the corresponding alcohols [13] as well as the synthesis and biological activity of the enantiomeric oxadiazoles (+)- $(1 R, 3 R, 4 R)$ and $(1 S, 3 S, 4 S)-42$ [15]. We have also obtained oxadiazoles $(+)-(1 R, 3 R, 4 R)$ and $(-)-(1 S, 3 S, 4 S)-1$ [36] in analogous fashion from these same alcohols, via the corresponding ketene dithioacetals. Recently, an alternative synthesis of the methyloxadiazole enantiomers (+)- and (-)-1 [14c] has been published along with their muscarinic activity in several systems. We report here further characterization of these compounds.

\section{Scheme 4}

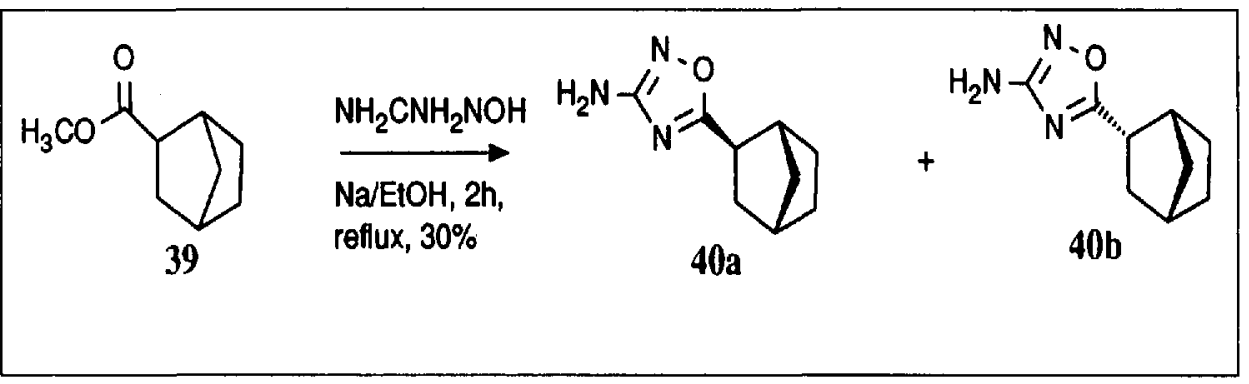

The carbocyclic analogue 40, was prepared (Scheme 4) from the known methyl 2-norbornanecarboxylate 39 by treatment with the sodium salt of hydroxyguanidine in $\mathrm{EtOH}$. This was obtained as a crystalline mixture of diastereoisomers $(40 \mathrm{a} / 40 \mathrm{~b}$ $3: 7)$ in $30 \%$ yield.

\section{Results}

\subsection{Oxazolidinone and 5-MFT Analogues}

The in vitro muscarinic activity for all the compounds under study is presented in the Table. It is recapitulated that with the exception of $\mathbf{4 0}$ all compounds tested are enantiomerically pure. Additionally, in the azabicycloheptane series, compounds with analogous configuration are grouped together for the sake of clarity. Also it should be noted that the D-histidine derived ( $4 R$ )enantiomer of $(4 S)-8$ has been shown to be completely inactive as a muscarinic agonist [10][11c]. As a result, analogs of 8 from the enantiomeric ( $4 R$ )-series were not investigated. The pharmacological profile of the oxazolidinone 8 is almost identical to that of pilocarpine. Relative to pilocarpine, 8 displays slightly lower ileal and ganglion functional potencies $\left(\mathrm{pD}_{2}\right.$ values) as well as a somewhat lesser ability to displace pirenzepine. Thiazolidinone analog 9, in which a S-atom is substituted for the ether $\mathrm{O}$-atom of oxazolidinone 8 , displays lower agonist activity in all the functional tests. The largest change was in the ganglion where 9 exhibited both diminished potency and efficacy (maximal response) relative to the parent 8 . There is a slight drop in the ileal efficacy of 9 without change in ileal potency and in the hippocampus model, while there is a reduction in potency, efficacy is maintained. The lower CD affinity of 9 relative to 8 is consistent with the overall lower functional activity of 9 . The pharmacological profiles of thiazolidinone 9 and thiolactone $\mathbf{2}$ are clearly not identical. This stands in contrast to the virtual pharmacological identity of $\mathbf{8}$ and pilocarpine which are related by the same atomic replacement. Thiazolidinone 9 and thiolactone 2 are equiactive in the ileum model, while in the ganglion model, 2 exhibits substantial- ly greater agonist activity than 9 being roughly tenfold more potent as well as slightly more efficacious. In the hippocampus model, 2 and 9 display similar potencies, but 9 is a more active agonist exhibiting almost full maximal response, while 2 only displays half maximal response (partial agonism). The more potent pirenzepine binding of 2 relative to 9 indicates that 2 has a significantly greater antagonist (potential partial agonist) component to its activity. For oxazolidinethione 10, in which a $S$-atom is substituted for the carbonyl $\mathrm{O}$-atom of $\mathbf{8}$, lower overall agonist activity is also observed. This compound is a clearcut partial agonist in the ileum and hippocampal models where the efficacy is only half that of the muscarine standard. In the ganglion model, 10 displays significantly reduced agonist potency but efficacy comparable to 8 . The binding data for $\mathbf{1 0}$ are consistent with the functional data. In particular, the greater pirenzepine binding of 10 relative to 8 and 9 is indicative of a greater antagonist component for 10 consistent with the partial agonism found in the ileum and ganglion models. The thiazolidinethione 11, where both $\mathrm{O}$-atoms of 8 are replaced with $\mathrm{S}$, was inactive in the ileum and hippocampus models and displayed significantly reduced activity (potency and efficacy) in the ganglion model. In contrast, the CD binding of 11 is comparable to that of 9,10 , and 12 . The pirenzepine binding of $\mathbf{1 1}$ is greater than that of $\mathbf{1 0}$ which only displays $50 \%$ efficacy in the hippocampus and ileum models. In all likelihood, 11 acts as an antagonist in the latter models. The lactam analogue 12 in which the ether $\mathrm{O}$-atom of 8 is replaced with a $\mathrm{CH}_{2}$ group exhibits slightly reduced agonist potency in the ileum model and significantly reduced potency in the ganglion model relative to 8. The efficacies for $\mathbf{1 2}$ are, however, comparable to those displayed by 8 . Again the very weak pirenzepine binding of 12 is consistent with its good efficacy.

5-Methyfurmethide (5-MFT) is a potent classical quaternary muscarinic agonist [37]. The thiophene analog 13 where the sole furan $\mathrm{O}$-atom of 5-MFT is exchanged for $\mathrm{S}$ is 100 -fold less potent than 5-MFT overall and hence only moderately active. In the aforementioned toxicology 
Table. Data from Functional Tests and Binding Assays

\begin{tabular}{|c|c|c|c|c|c|c|c|c|}
\hline Compound & $\mathrm{pD}_{2}$ ileum & eff. $[\%]$ & $\mathrm{pD}_{2}$ gang & eff. $[\%]$ & $\mathrm{pD}_{2}$ hippo & eff. $[\%]$ & $\mathrm{CD}$ (nM) & Pir (nM) \\
\hline$(+)-(3 S, 4 R)$-pilocarpine & 5.9 & 84 & 6.5 & 130 & 5.6 & 100 & 80 & 960 \\
\hline$(+)-(3 S, 4 R)$-isopilocarpine & 4.4 & 77 & 5.0 & 125 & 5.1 & 100 & 430 & 1800 \\
\hline$(+)-(3 S, 4 R)-2$ & 5.3 & 70 & 6.5 & 130 & 5.3 & 50 & 54 & 435 \\
\hline$(+)-(3 S .4 R)-3$ & 4.2 & 66 & 5.2 & 110 & 4.5 & 95 & 845 & 5150 \\
\hline$(+)-(3 S, 4 R)-4$ & 5.6 & 23 & 5.2 & 38 & - & - & 45 & 51 \\
\hline$(+)-(3 S, 4 R)-5$ & 4.5 & 34 & 5.7 & 60 & $<4$ & - & 445 & 1800 \\
\hline \multirow[t]{2}{*}{$(+)-(3 S, 4 R)-6$} & 5.2 & 22 & 5.9 & 65 & $<4$ & - & 45 & 110 \\
\hline & \multicolumn{8}{|c|}{ Oxazolidinone Analogs } \\
\hline$(+)-(4 S)-8$ & 5,4 & 93 & 6.1 & 132 & 5.6 & 100 & 100 & 2900 \\
\hline$(+)-(4 S)-9$ & 5.3 & 70 & 5.6 & 95 & 5.2 & 90 & 300 & 2650 \\
\hline$(+)-(4 S)-10$ & 5.4 & 50 & 5.4 & 115 & 5.2 & 60 & 210 & 1000 \\
\hline$(+)-(4 S)-11$ & $<4$ & - & 5.2 & 74 & $<4$ & - & 320 & 440 \\
\hline$(+)-(45)-12$ & 5.0 & 80 & 5.3 & 140 & - & - & 290 & $>10000$ \\
\hline 5-MFT & 6.8 & 115 & 7.1 & 63 & 5.8 & 129 & 5.6 & 1410 \\
\hline \multirow[t]{2}{*}{13} & 4.8 & 94 & 5.2 & 117 & 5.4 & 57 & 240 & 2400 \\
\hline & \multicolumn{8}{|c|}{ 2-Azabicyclo[2.2.1]heptanes } \\
\hline$(+)-(1 R, 4 S, 6 R)-27$ & 4.5 & 71 & 4.1 & 130 & 5.7 & 53 & 1445 & 3162 \\
\hline$(+)-(1 R, 4 S, 6 R)-28$ & 5.2 & 32 & $<4$ & - & 5.3 & 16 & - & - \\
\hline$(-)-(1 R, 4 S, 6 R)-37$ & 6.5 & 127 & 6.6 & 115 & 6.6 & 125 & - & - \\
\hline$(-)-(1 R, 4 S, 6 R)-38$ & $<4$ & - & 5.0 & 68 & $<4$ & - & - & - \\
\hline$(-)-(1 S, 4 R, 6 S)-27$ & 4.9 & 35 & 4.4 & 33 & 5.3 & 41 & 1950 & 2290 \\
\hline$(-)-(1 S, 4 R, 6 S)-28$ & 4.7 & 33 & $<4$ & - & 5.6 & 25 & 3390 & 3020 \\
\hline$(+)-(1 S, 4 R, 65)-37$ & 5.3 & 101 & 6.3 & 47 & 5.9 & 32 & - & - \\
\hline \multirow[t]{2}{*}{$(+)-(1 S, 4 R, 6 S)-38$} & $<4$ & - & 4.2 & 81 & $<4$ & - & 457 & 890 \\
\hline & \multicolumn{8}{|c|}{ 1-Azabicyclo[2.2.1] heptanes } \\
\hline$(+)-(1 R, 3 R, 4 S)-41$ & 7.1 & 84 & 4.0 & 154 & - & - & 41 & $>10000$ \\
\hline$(+)-(1 S, 4 R, 6 S)-1$ & 9.1 & 100 & - & - & 8.7 & 100 & 0.19 & 68 \\
\hline$(+)-(1 S, 4 R, 6 S)-42$ & 8.8 & 87 & 10.2 & 36 & 9.8 & 116 & 0.29 & 40 \\
\hline$(-)-(1 S, 3 S, 4 R)-41$ & 6.9 & 93 & 4.0 & 95 & - & - & 4.7 & 9120 \\
\hline$(-)-(1 S, 3 S, 4 R)-1$ & 8.5 & 89 & - & - & 7.6 & 117 & 0.44 & 174 \\
\hline$(+)-(1 S, 3 S, 4 R)-42$ & 8.1 & 121 & 9.0 & 63 & 8.5 & 107 & 5.25 & 348 \\
\hline 40 & $<4$ & - & $<4$ & - & $<4$ & - & - & - \\
\hline Muscarine & 6.8 & 100 & 7.4 & 100 & 5.9 & 100 & 12 & 5680 \\
\hline Oxotremorine & 7.1 & 100 & 8.0 & 55 & 7.1 & 100 & 2.8 & 113 \\
\hline Arecoline & 6.5 & 100 & 6.6 & 80 & 6.6 & 100 & 20 & 1740 \\
\hline RS86 & 6.1 & 100 & 6.7 & 80 & - & - & 87 & 765 \\
\hline
\end{tabular}

The SEM for all $\mathrm{pD}_{2}$ determinations is less than or equal to 0.2 . The maximal SEM for the binding $I C_{50}$ values is $5 \%$.

studies [12],13 was found to be more toxic than 5-MFT. It is now clear that the toxicity observed for $\mathbf{1 3}$ cannot be related to a muscarinic effect.

\subsection{Azabicycloheptanes}

Both enantiomeric 6-acetoxy-2azabicyclo[2.2.1] heptanes (+)- and (-)-27 have very low activity as agonists in all the preparations tested which is completely abolished in the corresponding $N$-methyl analogs, (+)- and (-)-28. Replacement of acetate of 27 by methyloxadiazole to give 37 results in a dramatic increase in activity, but has different effects in the different functional models. For both the secondary amines (+)- and (-)-37, there is an increase in activity that is most marked for the ganglion; however, (-)-37 experiences a larger increase in ileal and hippocampal activity than its enantiomer, making it an overall more potent and efficacious compound. The $N$-methyl-oxadiazoles (+)-and (-)-38 decrease in activity at both ileum and hippocampus relative to the acetates, but display weak activity in the ganglion, where the acetates were totally inactive.

The 3-acetoxy-1-azabicycloheptanes 41 present a remarkable profile in functional tests. Both (+)- and (-)-41 are ca. 1000 times more active in the ileum than in the ganglion, and although there is a 10fold difference in $\mathrm{CD}$ binding affinity, there is no substantial difference in functional activity between the enantiomers. Methyloxadiazole (+)-( $1 R, 3 R, 4 R)-\mathbf{1}$ has been reported to be ' $50-60$ times selective for the ileum over the ganglion muscarinic receptor' [14c]. In our tests, (+)$(1 R, 3 R, 4 R)-1$ is the more potent enantiomer, and has only marginal selectivity for the ileum compared to the hippocampus. Its weaker enantiomer $(-)-(1 S, 3 S, 4 S)$ 1 is 12 -fold more potent in the ileum than in the hippocampus. As expected for a more potent agonist, $(+)-(1 R, 3 R, 4 R)-\mathbf{1}$ displays higher $C D$ binding affinity.

The amino-oxadiazole (+)- $(1 R, 3 R, 4 R)$ 42 displays slightly lower activity in the ileum than its methyl congener (+)$(1 R, 3 R, 4 R)-1$, but is 12 times more potent in the hippocampus. Additionally, (+)-42 is 10 -fold more active in hippocampus than in ileum, which indicates a reverse selectivity to what is the case with (+)-1. For the amino-oxadiazole (-)-42, activity is overall an order of magnitude smaller 
than that of its enantiomer. Interestingly, in the ileum preparation ( + )- 1 is the most potent compound, followed by $(+)-42,(-$ -1 , and (-) -42 , in decreasing order. For the hippocampal preparation, the order is $(+)-42>(+)-1>(-)-42>(-)-1$. The methyloxadiazoles are, therefore, more potent in the ileum, whereas the amino-oxydiazoles are more potent in the hippocampus. In this case, the $C D$ binding affinities follow the order of the potencies in the ileum.

Comparison of the amino-oxadiazoles with the corresponding acetates shows that there are quantitatively different effects upon replacement of acetate by amino-oxadiazole: whereas for (-)-42 and $(+)-42$, the ileal activity is enhanced 10 or 80 times relative to $(-)-41$ and (+)-41, respectively, the corresponding potency on the ganglion is enhanced $100^{\prime} 000$ and 1.6 million times. This large increase in potency is, however, not matched by an increase in efficacy; the most potent compound in the ganglion elicits only $36 \%$ of the maximal activity elicited by muscarine.

\section{SAR Discussion}

\subsection{Background}

The interpretation of muscarinic agonist SAR data in particular in terms of a receptor-ligand molecular recognition process is complicated by the existence of receptor subtypes as well as by receptor reserve phenomena [38]. Different tissues which are selected for functional tests serve only as models of homogeneous receptor populations but invariably have varying amounts of heterogeneity. Furthermore, even systems having the same homogeneous receptor populations can show different functional responses (potency and efficacy) depending on the number of receptors and coupling mechanisms present [39]. There are almost certainly subtle differences in the interaction of an agonist ligand with the different muscarinic receptor subtypes. Nevertheless, fundamental structural features which are important for a muscarinic agonist activity have been well established which are seemingly common to all subtypes. A cationic function (e.g. quaternary ammonium salt, protonated amine, sulfonium salt), which binds to an anionic receptor site and an H-bond acceptor moiety, which interacts with a receptor $\mathrm{H}$-bond donor, are essential for good muscarinic agonist activity. A hydrophobic binding interaction at a specific site (where the acetyl methyl group of acetylcholine binds and for which a methyl group appears to be optimal) also can contribute significantly to agonist activity [40]. Precise spatial orientation(s) [41] of these ligand moieties and the absence of other disrupting elements are the final requirements for agonist activity.

\subsection{Receptor Model}

Based on the SAR of the extremely potent muscarinic agonist oxadiazole 1 two $\mathrm{H}$-bonds for this compound with the receptor have been postulated [14b]. In our previous study [9], a dynamic model for the binding agonists to the $\mathrm{m} 1$ muscarinic receptor was proposed which allows for the formation of two $\mathrm{H}$-bonds in a general fashion [42]. Pilocarpine, 5MFT, and 1 were fit to the model. In the model, a binding site consisting of the triad of residues Asp 105, Ser 109, and Ser 112 located on the third putative transmembrane idealized $\alpha$-helix of the m1 receptor was hypothesized. Asp 105 serves as the cation binding site while both Ser 109 and Ser 112 are capable of acting as $\mathrm{H}$ bond donors. Furthermore, the side chains of these residues have torsional freedom allowing a dynamic fit of a given agonist ligand with the receptor. The model does not account for the putative hydrophobic binding site. It should be noted that for the $\mathrm{m} 3$ receptor protein the residues from Asp 105-Ser 112 are conserved while for the $\mathrm{m} 2$ and $\mathrm{m} 4$ receptor proteins there is a single variation with a valine residue in place of Ala 108

The accomodation of oxadiazole 1 in this model is ideal (Fig. I). An optimal salt bridge is formed between Asp 105 and the protonated tertiary amine function. Additionally Ser 109 and Ser 112 form good $\mathrm{H}$ bonds to the $\mathrm{N}$-atoms of the oxadiazole ring. Pilocarpine (Fig. 2) was accomodated in the model with Asp 105 binding the N(3)-protonated imidazole, Ser 109 forming a $\mathrm{H}$-bond to the lactone carbonyl $\mathrm{O}$ atom and Ser 112 forming a $\mathrm{H}$-bond to the lactone ether $\mathrm{O}$-atom. In this model both of the Ser-lactone O-atom $\mathrm{H}$-bond contacts were good (1.9 A). However, the carbonyl $\mathrm{O}$-atom of an ester function is known to be a better acceptor than the ester ether $\mathrm{O}$-atom [43]. In the case of 5MFT, only the furan oxygen is capable of H-bonding. This molecule was fitted to the model with Asp 105 binding the qua-

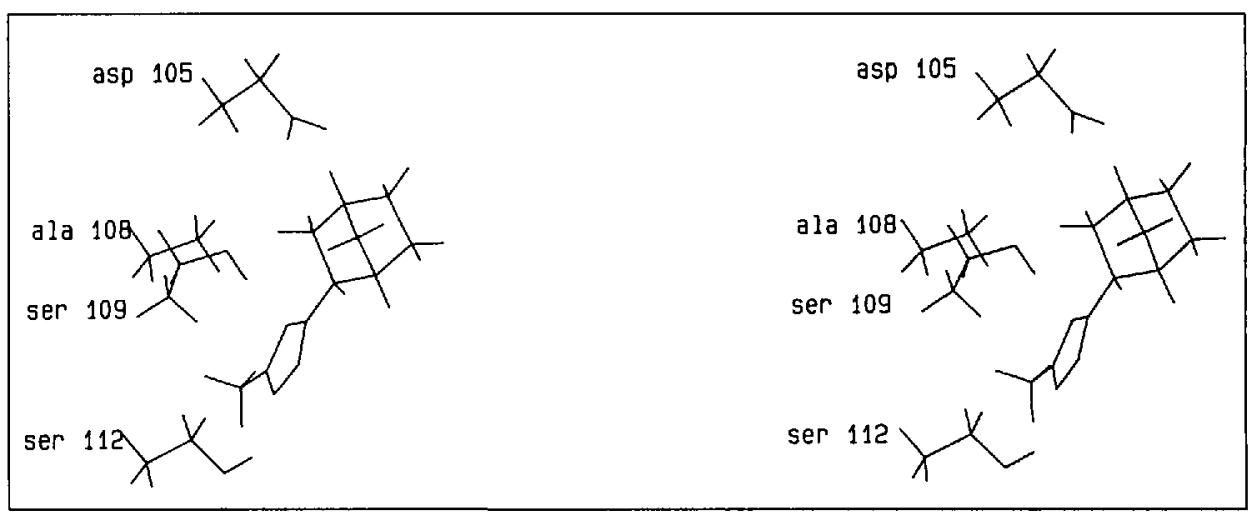

Fig. 1. Crossed stereoscopic view of the binding model of protonated oxadiazole 1 and the simplificd human $\mathrm{m} /$ muscarinic receptor. The model of the receptor consists of amino acid side chains Asp 105 , Ala 108, Ser 109 and Ser 112 with their $\mathrm{C}(\alpha)$-atoms placed on a standard $\alpha$-helix [42]. Compound 1 is docked manually to Asp 105, Ser 109, and Ser 112. Subsequent geometry optimization was carried out with MAXIMIN2(SYBYL) using Gasteiger-Hücke/ charges and keeping all Ca-atoms and their ligand atoms as one rigid aggregate. The final geometry shows close contacts of $i$ ) one of the two oxygens of Asp 105 with the ammonium nitrogen of 1, ii) the oxygen of Ser 109 with the 4 '-oxadiazole ring nitrogen, and iii) the oxygen of Ser 112 with the 2'-oxadiazole ring nitrogen. The Me group of 1 fits into the region between the side chains of Ser 109 and Ser 112.

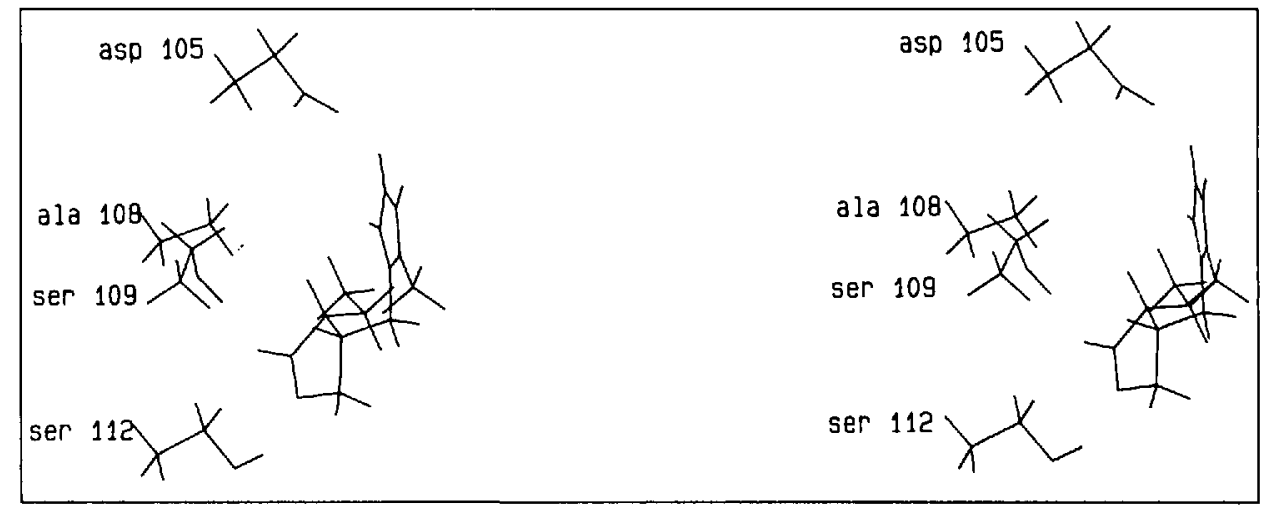

Fig. 2. Crossed stereoscopic view of the binding model of protonated pilocarpine and the simplified human $\mathrm{ml}$ muscarinic receptor (derived as in Fig. 1 ). The final geometry shows close contacts of $i$ ) one of the two oxygens of Asp 105 with the imidazolium nitrogen, $i i)$ the oxygen of Ser 109 with the carbonyl oxygen, and iii) the oxygen of Ser 112 with the ether oxygen. 
ternary ammonium function and Ser 109 donating a $\mathrm{H}$-bond to the furan $\mathrm{O}$-atom [9].

\subsection{Discussion}

This SAR study using $\mathrm{S}$ and $\mathrm{CH}_{2}$ to replace the $\mathrm{O}$-atom in the oxazolidinone 8 further supports the basic tenets of muscarinic agonist activity requirements as well as our hypothetical receptor model. Due to the aforementioned difficulties in interpreting muscarinic agonist activity in terms of receptor subtype components, the muscarinic agonist activity discussed here will for convenience be discussed in terms of a ligand interaction with an 'archetypal' muscarinic receptor. Indeed, despite considerable effort toward preparing subtypeselective muscarinic agonists few reports of such compounds exist [44], and in these cases the evidence for true or significant subtype selectivity is marginal or equivocal.

\subsubsection{5-MFT and Oxazolidinone Analogues}

The findings on exchange of the $S$ atom or $\mathrm{CH}_{2}$ group for $\mathrm{O}$ with oxazolidinone 8 and of S for $O$ with 5-MFT provide insight into the nature and importance of $\mathrm{H}$-bonding to muscarinic agonist activity. Thiophene $\mathbf{1 3}$ is roughly two orders of magnitude less potent than the analogous furan agonist 5-MFT. There are two factors which come into consideration regarding the diminished activity of 13. First$\mathrm{ly}$, a thioether $\mathrm{S}$-atom is a very poor $\mathrm{H}$ bond acceptor [45], and the important $\mathrm{H}$ bond to the furan O-atom of 5-MFT is lost in the case of 13 . Secondly, the S-atom has greater steric demand, and has somewhat longer bonds which may unfavorably affect the disposition of the methyl and trimethylammonium involved in hydrophobic and ionic binding, respectively. A good example for the effects on muscarinic activity upon $\mathrm{S}$ replacement of the $\mathrm{O}$ atom in a planar aromatic ring is the sulfur analogue, thiadiazole 43 , of oxadiazole 1 [14d]. In 43, the important H-bonding to the two oxadiazole ring $\mathrm{N}$-atoms is maintained while the steric and or geometrical perturbation(s) caused by $S$ relative to $O$ attenuate activity by less than an order of magnitude [14d]. Thus, it would seem that the loss of the $\mathrm{H}$-bonding interaction is the major cause of the diminished activity of thiophene 13 , with the geometric perturbation caused by $S$ being of lesser importance in this case.

The results of exchanging the different $\mathrm{O}$-atoms of oxazolidinone 8 for $\mathrm{S}$ or $\mathrm{CH}_{2}$ require careful interpretation. The similar overall agonist activity of the thiazolidinone 9 and oxazolidinonethione $\mathbf{1 0}$ was somewhat unexpected. In our previous study [9], we had concluded that an Hbonding interaction involving the lactone carbonyl O-atom of pilocarpine was of primary importance to activity while the ether $\mathrm{O}$-atom assumes a secondary role in the form of a weak H-bonding effect. This conclusion was based in part on the fact that, relative to pilocarpine, the thiolactone 2, lacking the lactone ether $\mathrm{O}$-atom exhibits moderately diminished agonist activity while the tetrahydrofuran and lactol analogs 5 and 7, lacking the lactone carbonyl O-atom, have dramatically reduced agonist activity. As $\mathbf{8}$ shows a biological profile very similar that of pilocarpine, it would appear reasonable to assume a priori that, for $\mathbf{8}$, the relative importance of the two oxazolidinone $\mathrm{O}$ atoms corresponds to that which is the case for pilocarpine. If this is the case, then one might expect a dramatic drop in activity of $\mathbf{1 0}$ in which the carbonyl O-atom of $\mathbf{8}$ is replaced with $\mathrm{S}$. That the drop in activity is only moderate was at first sight surprising to us. There are two possible explanations for maintenance of activity in 10 despite the loss of the carbonyl Oatom. Firstly, the ether O-atom of $\mathbf{1 0}$ has intrinsically better H-bond accepting potential than that of 8 , and may act as a more important H-bond acceptor. Secondly, the dithiocarbamate thiocarbonyl S-atom present in $\mathbf{1 0}$ may, unlike a thioether Satom, in fact, be a good H-bond acceptor. Indeed, a crystal structure exists which demonstrates that a dithiocarbamate thiocarbonyl function can act as an H-bond acceptor [46a], and other crystallographic and IR evidence exists demonstrating that the thiocarbonyl function in general can act as a good H-bond accepting moiety $[46 \mathrm{~b}, \mathrm{c}]$. Unlike the H-bond to an ether, the $\mathrm{H}$-bond to a carbonyl has a highly directional nature. Even though the thiocarbonyl of $\mathbf{1 0}$ may intrinsically be a good $\mathrm{H}$ bond acceptor, the geometrical perturbation introduced by replacement of the carbonyl with thiocarbonyl function could still be expected to lead to a loss of agonist activity for 10 relative to 8 . It is our opinion that $\mathrm{H}$-bonding to the thiocarbonyl and to the ether $\mathrm{O}$-atom are both factors which contribute to the activity of $\mathbf{1 0}$. In the case of compounds 9 and 12, only the carbonyl $\mathrm{O}$-atom is capable of $\mathrm{H}$-bonding. The thioether S-atom of the thiazolidinone 9 has poor if any intrinsic $\mathrm{H}$-bonding capacity, and the $\mathrm{CH}_{2}$ group of lactam 12 clearly has none. For agonist activity, the greater importance of the carbonyl oxazolidinone $\mathrm{O}$-atom of 8 relative to the ether $\mathrm{O}$-atom is confirmed because 9 and 12 exhibit comparable agonist activity which is only moderately diminished relative to 8 . In the case of thiazolidinethione 11, only the thiocarbonyl function comes under con- sideration for having $\mathrm{H}$-bonding potential. Significant agonist activity is seen for 11 only in the ganglion models. This indicates that for the muscarinic receptor(s) present in this system, the thiocarbonyl of $\mathbf{1 1}$ is indeed participating in the putative H-bonding interaction important for muscarinic agonist activity. The virtual lack of agonist activity for $\mathbf{1 1}$ in the ileum and hippocampus models must, however, be addressed. In these models it would appear that 11, which is a partial agonist in the ganglion model, acts as an antagonist. Receptor subtype effects and or different receptor coupling mechanisms could be operating such that 11, due to greater steric demand relative to 8,9 , and 12 , binds to and acts preferentially on an antagonist receptor(s) state in ileum and hippocampus models.

\subsubsection{Azabicyclo[2.2.1]heptanes}

It is instructive to compare the biological activities of the azabicycloheptyl acetates with their 1,2,4-oxadiazole analogues. Obviating the differences in hydrolytic stabilities, structural comparisons may be made [19]. In principle, the acetate moiety can accept $\mathrm{H}$-bonds to both the ether and the carbonyl $\mathrm{O}$-atom, as discussed for the lactone of pilocarpine, whereas for 1,2,4oxadiazoles all three heteroatoms are potential H-bond acceptors. The crystal structure of the quinuclidine analogue of $\mathbf{4 2}$ [47], as well as electrostatic potential calculations [14a] indicate that both $\mathrm{N}$-atoms should be considered as intrinsically stronger $\mathrm{H}$-bond acceptors than the $\mathrm{O}$ atom.

For the 1-azabicyclo[2.2.1]heptanes, muscarinic activity is greater for the isomers with analogous configuration to $(+)$ $(1 R, 3 R, 4 R)-42$, that is $(+)-(1 R, 3 R, 4 R)-1$ and $(+)-(1 R, 3 R, 4 S)-41$, even though for 41 the difference between the enantiomers is marginal.

For $(+)-(1 R, 3 R, 4 S)-41$, the acetate group can be accomodated in at least two low energy conformations, labelled $A$ and $\mathrm{B}$, to our receptor model, as shown in Fig. 3 . In these conformations, the acetates are trans, and are characterized by the torsion angles $\mathrm{C}(2)-\mathrm{C}(3) \mathrm{O}-\mathrm{Cof} 171^{\circ}(\mathrm{A})$ and $71^{\circ}$ (B), for $(+)-(1 R, 3 R, 4 S)-41$, and with torsion angles of $-172^{\circ}(A)$ and $-71^{\circ}(B)$ for its enantiomer (not shown). In both these conformations, a good salt bridge with Asp 105 can be modelled, placing an $\mathrm{O}$ atom within $\mathrm{H}$-bonding distance of Ser 109. In conformation $A$, the acetate ether O-atom accepts an H-bond from Ser 109 , whereas in conformation $\mathrm{B}$ the carbonyl $\mathrm{O}$-atom accepts an $\mathrm{H}$-bond, also from Ser 109. In all of these cases, however, Ser 112 is too distant to provide a second $\mathrm{H}$-bond to either the ether or the carbonyl O- 
atoms. The corresponding oxadiazole $(+)-(1 R, 3 R, 4 R)-1$ fits in analogous fashion, but both $\mathrm{H}$-bonds to Ser 109 and Ser 112 can be formed (see Fig. 1). The main contribution to the potency is nevertheless the coulombic interaction, as indicated by the fact that the carbocyclic analogue $\mathbf{4 0}$ is totally lacking in affinity and activity. Optimal localization and directionality of the H-bonds to both oxadiazole ring $\mathrm{N}$ atoms as well as the greater intrinsic $\mathrm{H}$ bonding ability of the oxadiazole compared to the ester moiety [14a] provide an explanation for the high potency of these compounds.

In the 2-azabicyclo[2.2.1] heptane series, the secondary amine acetates $\mathbf{2 7}$ are weak agonists, and their corresponding oxadiazoles $\mathbf{3 7}$ are more potent. This is in keeping with what was observed in the 1azabicycloheptane series, and can be interpreted in terms of the geometrical differences which allow two $\mathrm{H}$-bonds to be formed in the case of the oxadiazoles, whereas only one can be formed by the acetates. The secondary amino-oxadiazole (-)-(1R,4R,6R)-37 is the most potent compound in this series, being also a full agonist in all three preparations, with potency comparable to that of arecoline [29]. This compound could be accommodated to our model (Fig. 4), with the protonated 2-azabicycloheptane secondary amine function forming a bidentate salt bridge with Asp 105, in which both ammonium $\mathrm{H}$-atoms are in close contact $(1.6 \AA)$ to the carboxylate $\mathrm{O}$-atoms. The lower activity of the corresponding $N$-methyl compounds 38 is surprising, because it is known that arecoline is a more potent agonist than the corresponding secondary amine lacking the Me group [7]. The inability to form a favorable bidentate salt bridge in the case of 38 could account for its lesser but not complete lack of activity. The very low activity of $\mathbf{3 8}$ is better attributed to steric disturbance caused by the $N$-methyl group in the case of the 2-azabicyclic ring system.

From the foregoing discussion, it can be seen, that the oxadiazole moiety can mimic an acetate moiety, and perform analogous function in the muscarinic receptors only for a specific geometry of receptor-ligand interactions. For the 1azabicycloheptanes, the replacement is successfully mimicking the acetate group, with enormous increases in activity, but for a different geometry the result is the opposite: the same replacement in the $N$ methyl-2-azabicycloheptanes results in abolition of an already weak activity. Biological activity is, therefore, not an invariant property of a geometrical arrangement of a subset of ligand atoms, but is contingent on parameters of the whole
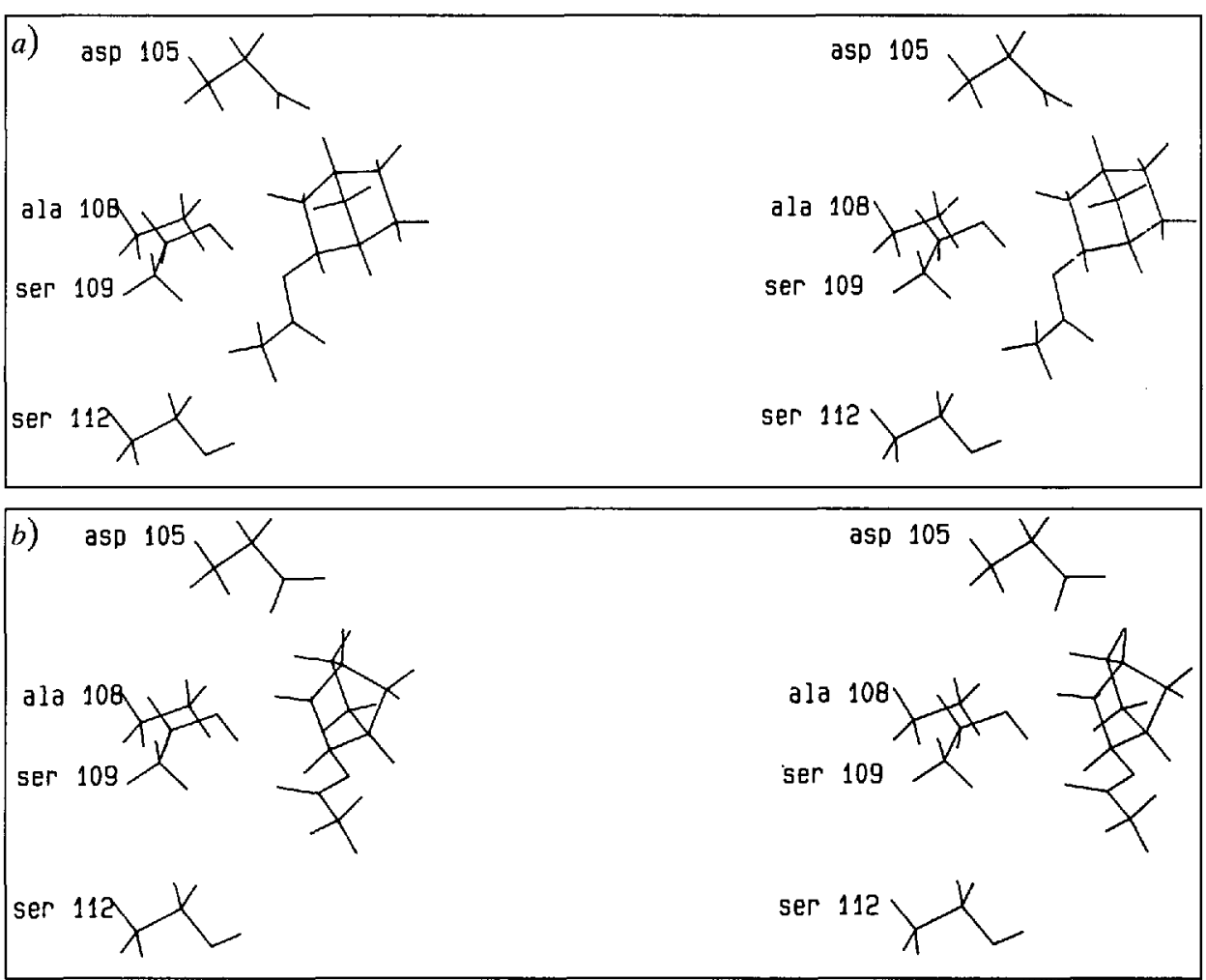

Fig. 3. Crossed stereoscopic views of two binding models $A$ and $B$ of $(+)-\mathbf{4 1}$ and the simplified human $\mathrm{ml}$ muscarinic receptor (derived as in Fig. 2). $a$ ) and $b$ ) depict the final geometries obtained for conformation A and B (sec text) of (+)-41, respectively. With both conformations close contacts are formed $i$ ) between one of the two oxygens of Asp 105 with the ammonium nitrogen of (+)-41 and ii) between the oxygen of Ser 109 with the ether oxygen $(a)$ and the carbonyl oxygen $(b)$ of $(+)-41$. In none of the two models $(+) 41$ accepts a hydrogen bond from Ser 112. In the model depicted in $a$, the methyl group of $(+)-41$ fits into the region between the side chains of Ser 109 and Ser 112.

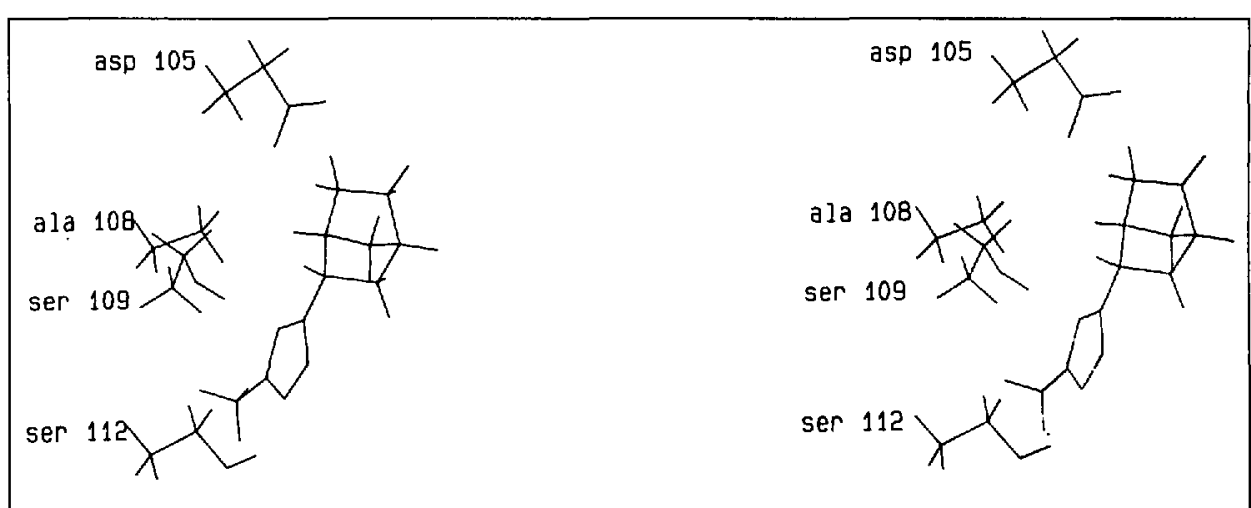

Fig. 4. Crossed stereoscopic view of the binding model of protonated oxadiazole (-)-37 and the simplified human $\mathrm{m} 1$ muscarinic receptor (derived as in Fig. 1). The final geometry shows close contacts of $i$ ) both oxygens of Asp 105 with the ammonium nitrogen of $(-)-37, i i)$ the oxygen of Ser 109 with the $4^{\prime}$ oxadiazole ring nitrogen, and iii) the oxygen of Ser 112 with the 2 ' oxadiazole ring nitrogen. The primary methyl group of (-)-37 fits into the region between the side chains of Ser 109 and Ser 112.

molecule and on interactions external to the molecules themselves, i.e. with the receptor. It is, nevertheless, useful to attempt to find analogies between biologically active molecules, and for this purpose the concepts of isosterism and bioisosterism have been widely used.

\section{Bioisosterism and Isosterism}

\subsection{History}

The term isostere was originally defined precisely by Langmuir [48] to relate molecules or ions which are isoelectronic. 'Comolecules are thus isosteric if they contain the same number and arrangement of electrons. The comolecules of isosteres must, therefore, contain the same number of atoms. The essential differences between isosteres are confined to the charges on the nuclei of the constituent atoms'. From this definition, it follows that Langmuir isosteres are also alike in shape. The central theme to Langmuir's concept of isosterism concerns the arrangement of electrons; however, and not steric aspects as they currently understood. Langmuir 
went on to postulate that isosteres which have the same charge should have similar physico-chemical properties. Notonly was this demonstrated, but the concept of isosterism has been used to predict the existence of molecules which were later discovered such as ketene [49]. Grimm later formulated the 'hydride displacement law' [50] in which addition of hydrogen to an atom confers on the aggregate the properties of the atom of next highest atomic number. An isoelectronic relationship exists among such aggregates which were named pseudoatoms (e.g. $\mathrm{CH}_{2}, \mathrm{NH}, \mathrm{O}$ ). This formulation of Grimm's served in some circles to expand Langmuir's concept of isosterism although Grimm himself certainly did not intend this [51]. Sometime later, Goubeau pointed out [52] the incongruity inherent in linking or incorporating the postulated close physical analogy of isosteres to the original formal definition. This was occassioned by the study of boron-nitrogen compounds (borazanes) which, regarding physical properties, often differ significantly from their corresponding carbon (Langmuir) isosteres.

Erlenmeyer proposed his own definition [53] of isosteres as elements, molecules or ions in which the peripheral layers of electrons may be considered identical, and considered it an expansion of Langmuir's definition. As Hansch has pointed out [54], this definition is meaningless in light of modern electronic bonding theory. Erlenmeyer's primary interest was, however, in relating compounds exhibiting analogous biological (antigen antibody cross reactivity) and/or physical properties (crystal form). To relate such compounds he sought underlying 'isosteric' structural analogies which he tried to codify. To this end, he linked then existing concepts of structural analogy. In doing so, he included well defined concepts of Langmuir (isosterism) and Grimm (pseudoatoms), but also extended beyond their clearly defined boundaries. Thus, Erlenmeyer's concept of isosteres encompasses Hinsherg's concept of ring equivalents [55] as well the classifications of other chemists including himself [8a] [53]. In these cases, the structural analogy is grounded in some phenomenological equivalence or similarity and is not derived from first principles. Whereas Langmuir's concept of isosterism is unequivocal and derives from first principles, $E r$ lenmeyer's concept is no longer clearly definable.

Erlenmeyer's ideas on the relationship between structure and biological activity have significantly influenced medicinal chemists. Particularly attractive to the medicinal chemist is the concept of related isosteric elements (an extension of
Grimm's concept of pseudoatoms) as partial structures which may confer analogous biological or physical properties on an entire molecule. This has obvious implications for the exploration of structure activity relationships. It is, therefore, not surprising that Erlenmeyer's language has also infiltrated medicinal chemistry. Currently, the word isostere appears frequently in the publications of organic and medicinal chemists where it is used along the lines set by Erlenmeyer [56]. Bioisosterism is a new term which medicinal chemists have widely adopted, and which confines Erlenmeyer's broader concept of isosteric analogy (which also included physical analogy) to the field of biology. As originally defined by Friedman [57], the concept of bioisoterism relates compounds 'which fit the broadest definition of isosteres and have the same type of biological activity'. Such use of the word 'isosteres' causes problems, since an isosteric relationship cannot, in fact, be defined on a structural basis in an exact way or derived from first principles. To circumvent this problem attempts have been made to catalog isosteric groups. Nevertheless, in the context of medicinal chemistry, isosterism remains poorly defined, and it is clearly not desirable to compound the vagueness associated with it in using it to define another concept, namely bioisosterism. Hansch realized this problem and redefined bioisosterism [54] omitting structural constraint. According to him, in the context of a given biological parameter, bioisosteres are molecules which elicit analogous responses. Burger has recently proposed [8a] an expansion of the Hansch definition of bioisosteres. Accordingly, molecules or groups which exhibit a related but not necessarily analogous biological response(s) (e.g. agonism or antagonism) and have some degree of structural and physical similarity are understood to be bioisosteres. He goes on to subclassify bioisosteres into classical and nonclassical types, carefully avoiding the word isosterism. Classical bioisosterism applies to 'the cases that satisfy the conditions set forth by Langmuir, Grimm, and Erlenmeyer' and 'nonclassical bioisosterism refers to a more widely applicable set of compounds which cause qualitatively similar agonistic or antagonistic biochemical or pharmacological responses at the molecular level'. Unfortunately, both Hansch and Burger retain the confusing word bioisosterism. This is particularly problematic, since the words isostere and bioisostere are often used interchangeably. Given this situation, one encounters the paradox that not only must isosteres not necessarily be bioisosteres but also that bioisosteres must not necessarily be isosteres.

\subsection{Isosterism and Bioisosterism Revised}

Confusion and fundamental problems with the continued use of both the term isosterism and bioisosterism remain which call for their revision and/or renaming. We propose the word bioanalogue to take the place of bioisostere and adopt the definition of Hansch but expand its scope to accomodate groups or partial molecular structures as well as entire molecules. Thus, bioanalogs are molecules or groups which, in the context of a given biological parameter, elicit analogous responses [58]. For this term, the structural connotations present in the previous term bioisostere are removed. Ascribing a bioanalogous relationship to different partial molecular structures or groups is associated with problems. Thus, for a given set of groups bioanalogy may not necessarily be conserved over a wide range of molecules even with regard to a single biological parameter. Nevertheless, the concept of interchangeable groups which are potentially bioanalogous with regard to a single or many biological parameter(s) is undisputably, very useful. Indeed, for the medicinal chemist the greatest potential of the concept lies in systematic searching of a database to find group replacements which starting from a lead molecule could yield novel or useful active molecules.

The term isostere is so widespread that it can be maintained and continue to be used but only with regard to structure. It should, however, be redefined to be consistent with the current meaning of the adjective steric. Thus, isosteric literally means identical in size and shape, but to be useful isosteric must be subjectively defined to mean similar in size and shape. With this classification we propose the terms isosteric and non-isosteric bioanalogs to replace the terms classical and nonclassical bioisosteres.

\subsection{Guidelines for SAR Studies}

The SAR study presented in this paper provides guidelines for the application of isosteres and bioanalogs (bioisosterism) in-the context of modern medicinal chemistry. By careful choice of isosteric replacements (as defined by us above, in the sense of shape conservation) in an SAR study where the activity is consequent to a molecular recognition process, one may determine the relative importance and location of electronic and steric interactions in ligand-receptor complex(es). In the process of applying isosteric replacements necessary to differentiate electronic from steric effects, one may discover a ligand (drug) having desirable biological properties. Otherwise, an understanding of the molecular details of a ligand's interaction 
with its receptor(s) confers potential for design of ligands within or even outside of (de novo) the realm of structures known to act at the given receptor(s). The use of nonisosteric bioanalogs (nonclassical bioisosteres) is primarily of value in this process of the designing novel ligands.

Starting from pilocarpine, isosteric modification of the lactone function demonstrated that the lactone function accepts two $\mathrm{H}$-bonds from the muscarinic receptor(s). The results from the isosteric replacement study with oxazolidinone $\mathbf{8}$ supported the above conclusion and further delineated some of the steric constraints on agonist activity for this system. In this case, not only was the nature of the electronic interaction of the lactone elaborated, but one of the bioanalogs was deemed to have an overall biological profile of potentially therapeutic value [9][10]. Thus, with the knowledge that two $\mathrm{H}$ bond accepting interactions are important from the pilocarpine SAR one could search for ester group bioanalogs which meet this requirement imposing some size constraint. Then, after inspection of the available lead structures one could decide which structures are amenable to incorporation of such groups. Although the azabicycloheptane oxadiazoles were not designed as a consequence of the results from our pilocarpine SAR, it is clear that, in theory, one could have arrived at these compounds using the process described above. In practice the group at MSD wished to replace the labile ester group of arecoline with a stabile mimic [14a]. The discovery that the oxadiazole can not only enhance stability but also increase agonist potency led to its application to other aza ring systems.

\subsection{Conformation and Chirality}

Any consideration of isosterism has to take conformational parameters into account. Clearly, two conformations of the same molecule will not necessarily be isosteric; both, however, may be bioanalogous, if they can elicit similar biological activity. Indeed, we have recently proposed two distinct chair conformations of the same compound to be capable of equally good interaction in our model [59]. Thus, it must be considered whether a chemical modification of a compound affects its conformational preferences, and through this mechanism, its biological activity. The principle of biologically active conformers has been recently treated [60].

An additional difficulty may arise in attempting to relate molecules with analogous biological activity when racemic mixtures are used. As has been amply recognized by others, enantiomers interacting with chiral biomolecules may dif-

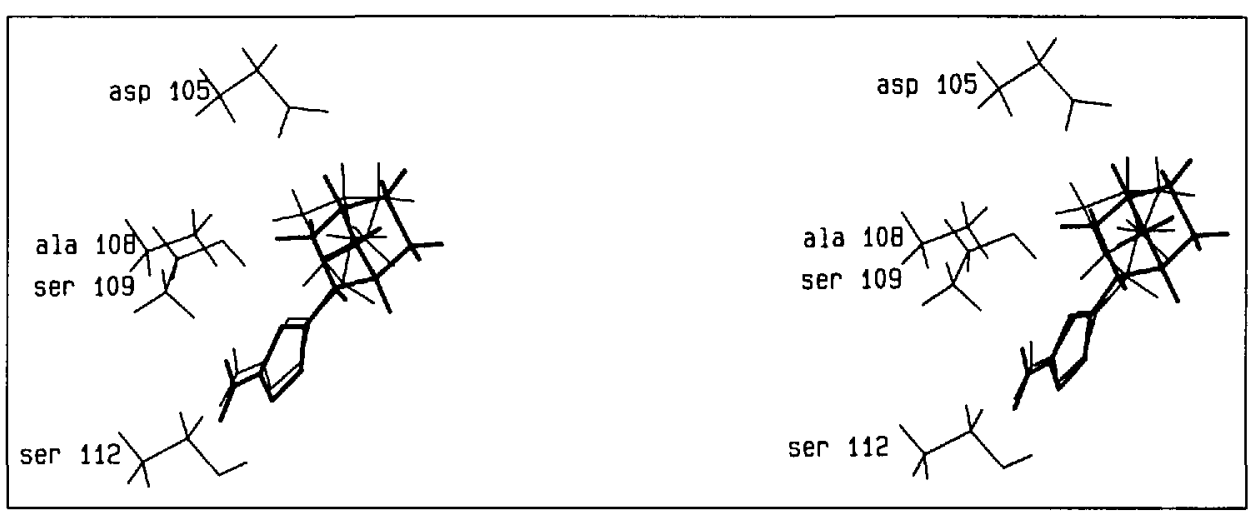

Fig. 5. Crossed stereoscopic view of the binding model of protonated amino oxadiazoles $(+)$ - and $(-)-42$ and the simplified human $m /$ muscarinic receptor (derived as in Fig. I). The more active $(+)$ 42 is depicted with thick lines. The final geometry shows for both enantiomers close contacts of $i$ ) one of the two oxygens of Asp 105 with the ammonium nitrogen of $(+)$-and $(-)-1, i i)$ the oxygen of Ser 109 with the 4'-oxadiazole ring nitrogens, and iii) the oxygen of Ser 112 with the 2'-oxadiazole ring nitrogen. The amino groups occupy the same region as is occupied by 1 . The accomodation resulted in the same receptor model and in different conformations for the enantiomers with torsion angles $<\mathrm{C}(2)-\mathrm{C}(3)-\mathrm{C}\left(5^{\prime}\right)-\mathrm{N}(4)^{\prime}>$ of $-45^{\circ}$ with $(+)-42$ and $1^{\circ}$ with (-)-42. With (+)-42, the C-atom closest to $\mathrm{C}(\beta)$ of Ala 108 is atom $\mathrm{C}(2)^{\prime}(4.8 \AA)$, whereas with $(-)-42$ it is atom $C(7)(4.0 \mathrm{~A})$.

fer greatly in their activities [61]. Enantiomers are not isosteric, as they are by definition non-superimposable, but they may be bioanalogous. Replacement of acetate by oxadiazole, in the 1-azabicycloheptanes, results in more potent compounds, and in an enhancement of the relative differences in muscarinic agonist potency between the enantiomers. This is in agreement with Pfeiffer's Rule [62], which refers to the generalization that the greater the biological activity of the racemate, the larger the difference in the activity of the enantiomers. This could be interpreted as the effect of a closer interaction between each of the enantiomers and the receptor, enhancing the stereodifferentiation. In other cases, however, Pfeiffer's Rule does not hold. The weaker agonists, the oxadiazolyl-2-azabicycloheptanes, have a larger difference in potency between the enantiomers. In the case of the oxazolidinone pilocarpine analogue 8 , only the $(4 S)$-isomer exhibits moderate activity, with the corresponding ( $4 R$ )-enantiomer being completely inactive. In contrast, for the l-azabicyclo[2.2.1] heptaneacetates, there is not much difference in potency between the enantiomers. In fact, both 1-azabicyclo[2.2.1] heptane-aminooxadiazoles $(+)-42$ and $(-)-42$ can be accomodated in our receptor model (see Fig. 5).

In conclusion, for constructing structure-activity relationships where biological activity is a consequence of a molecular recognition process, while certain empiricisms may be useful, structural considerations grounded in first principles are of prime importance. Thus, isosterism, carefully defined on purely structural considerations, may point the way to bioanalogous molecules with a desirable pharmacological profile.
We wish especially to thank Dr. H.W.G.M. Boddeke for allowing us to use his data regarding functional tests of the compounds described, Dr. P. Supavilai for the ligand binding assays, Dr. $R$. Amsiut for suggesting the synthesis of 40, and $D$. Buechler, U. Eggnauer, H. Gammonthaler, $M$. Marzi, and H.P. Weber for technical assistance.

Received: July 7, 1992

[1] W. H. Moos, R. E. Davis, R. D. Schwar,, E. R. Gamzu, Med. Res. Rev. 1988, $8,353$.

[2] a) E. K. Perry, B. E. Tomlinson, G. Blessed, K. Bergmann, P. H. Gibson, R. H. Perry, Br. Med.J. 1978, 2, 1457; b) E. K. Perry, R. H. Perry, in 'Biochemistry of Dementia', Ed. P. J. Roberts, John Wiley, London, 1980 , pp. 135-138.

[3] For a summary of clinical investigations of muscaric agonists see: J. Gray, A. Enz, R. Spiegel, Trends Pharmacol. Sci. Supplemen' 'Subtypes of Muscarinic Receptors IV' $1989,10,85-88$.

[4] a) H.H. Dale, J. Pharm. Exp. Ther. 1914, 6, 147; b) J. Physiol. 1933, 80, 10.

[5] N.J.M. Birdsall, N. Buckley, H. N. Doods, K. Fukuda, R. Giachetti, R. Hammer, H. Kilbinger, G. Lambrecht, E. Mutschler, N. Nathanson, A. North, R. Schwarz, Trends Pharmacol. Sci. Supplement 'Subrypes of Muscarinic Receptors IV' 1989, 10, VII.

[6] T.I. Bonner, Trends Neurrosci. 1989, 12, 148. It is to be noted that cloned muscarinic receptors are denoted with small case $m$ while pharmacologically defined receptors are denoted by capital $M$.

[7] B. Ringdahl, in 'The Muscarinic Receptors', Ed. J.H. Brown, Humana Press, Clifton, N.J., 1989, pp. 151-218.

[8] a) A. Burger, Fortschr. Arzncim.-Forsch. 1991, 31, 287; b) C.W. Thornber, Chem. Soc. Rev. 1979, 8, 563; c) C.A. Lipinski, Ann Reports Med. Chem. 1986, 21, 283.

[9] G. Shapiro, P. Floershcim, J. Boelsterli, R. Amstutz, G. Bolliger, H. Gammenthaler, G. Gmelin, P. Supavilai, M. Walkinshaw, $J$. Med. Chem. 1992, 35, 15. 
[10] For greater detail concerning the pharmacological profile of this compound and an SAR review of pilocarpine analogs see $G$. Shapiro, A. Enz, Drugs Future 1992, 7, 489.

[II] a) P. Sauerberg, J. Chen, E. Woldemussie, H. Rapoport, J.Med.Chem. 1989, 32, 1322; b) F.B. Gonzalez, J.P. Baz, M.R.I. Espina Tetrahedron Lett. 1989, 30, 2145; c) S.H. Hobbs, S.J. Johnson, S.R. Kesten, M.R. Pavia, R.E. Davis, R.D. Schwarz, L.L. Coughenour, S.L. Myers, D.T. Dudley, W.H. Moos, Bioorg. Med. Chem. Lett. 1991, I, 147.

[12] R.F. Ochillo, A.K. Chaturvedi, B.V. Rama Sastry, Toxicol.Appl.Pharmacol. 1978,43, 73.

[13] J. Boelsterli, U. Eggnauer, E. Pombo-Villar, H.P. Weber, M. Walkinshaw, R.O. Gould, Helv. Chim. Acta 1992, 75, 507.

[14] a) J. Saunders, M. Cassidy, S.B. Freedman, E.A. Harley, L.L. Iversen, C. Kneen, A.M. Macleod, K.J. Merchant, R.J. Snow, R. Baker, J. Med. Chem. 1990, 33, 1128; b) J. Saunders, S.B. Freedman, Trends Pharmacol. Sci. Supplement' Subtypes of Muscarinic Receptors IV' 1989, 70; c) G.A. Showell, R. Baker, J. Davis, R. Hargreaves, S.B. Freedman, K. Hoogsteen, S. Patel, R.J. Snow, J. Med. Chem. 1992, 35, 911; d) A. MacLeod, R. Baker, S.B. Freedman, S. Patel, K.J. Merchant, M. Roe, J. Saunders, $J$. Med. Chem. 1990, 33, 2052

[15] E. Pombo-Villar, K.H. Wiederhold, G. Mengod, J.M. Palacios, P. Supavilai, H.W.G.M. Boddeke, Eur. I. Pharmacol. Mol. Sect. 1992, 225, 317

[16] H. N. Doods, M. N. Mathy, D. Davidesko, K. J. Van Chareldorp, A. De Jonge, P. A. Van Zweiten, J. Pharm. Exp. Ther. 1987, 242, 257.

[17] a) H. Richards, Br.J. Pharmacol. 1989,99, 753; b) K. Gulya, P. Kása Neurochem. Int. $1989,15,153$; c) E. M. Meyer, D. B. Otero, J. Neurosci. 1988, 5, 1202.

[18] a) S. Lazareno, F. F. Roberts, Br.J.Pharmacol. 1989, 98, 309; b) P. Hadhazy, J.C. Szerb, Brain Res. 1977, 123, 311.

[19] To avoid the complications arising from differential hydrolysis of the acetates by endogenous cholinesterase, in case of the acetates, the assays were performed in the presence of physostigmine $10^{-6} \mathrm{M}$ and a nicotinic antagonist, hexamethonium $10^{-6}$ $\mathrm{M}$, to ensure the specificity of the muscarinic response.

[20] a) R. Hammer, C.P. Berrie, N.J. Birdsall, A.S.V. Burgen, E.C. Hulme Nature (London) $1980,283,90$; b) Watson. H. I. Yamamura, W.R. Roeske, Life Sci. 1983, 32, 2019

[21] A. Closse, H. Bittiger, D. Langenegger, A. Wanner, Naunyn-Schmiedeberg's Arch. Pharmacol. 1987, 335, 372.

[22] All new compounds were fully characterized, and presented satisfactory analytical and spectroscopic data.

[23] (4S)-10 hydrogen fumarate salt, m.p. 127$129^{\circ},[\alpha]_{\mathrm{D}}^{20}=+49\left(c=1.0, \mathrm{H}_{2} \mathrm{O}\right)$.

[24] R.P. Volante, Tetrahedron Lett. 1981, 22, 3119.

[25] (4S)-9 fumarate salt, m.p. $141-143^{\circ},[\alpha]_{D}^{20}=$ $+63\left(c=1.0, \mathrm{H}_{2} \mathrm{O}\right)$.

[26] S. C. Clough, R. Solomon, E. Crews, L. Jaques, A. Johnson, J. Forehand, J. Heterocycl. Chem. 1982, 22, 1489.

[27] (4S)-11 free base, m.p. $129-131^{\circ},[\alpha]_{D}^{20}=$ $+147(c=1.0, \mathrm{MeOH})$.
[28] (4S)-12 hydrogen chloride salt, m.p. 195 $198^{\circ},[\alpha]_{\mathrm{D}}^{20}=+50.5\left(c=1.0, \mathrm{H}_{2} \mathrm{O}\right)$.

[29] E. Pombo-Villar, H.P. Weber, H.W.G.M Boddeke, Bioorg. Med.Chem.Letl.1992, 2, 501.

[30] A. Dratva, Ph.D Thesis, University of Basel, 1987.

[31] (+)-(1R,4S,6R)-27: (+)-(1R,4S,6R)-6-Acetoxy-2-azabicyclo[2.2.1]heptane hydrogen fumarate, m.p. $138-140^{\circ},[\alpha]_{D}^{20}=+7.4(c=$ $0.5, \mathrm{MeOH})$

[32] (+)-28: (+)-(IR,4S,6R)-6-Acetoxy-2-methyl-2-azabicyclo[2.2.1] heptane hydrogen fumarate, m.p. $110-113^{\circ}\left(\mathrm{dec}\right.$.) $[\alpha]_{\mathrm{D}}^{20}=+$ $1.3(c=1.0, \mathrm{MeOH})$.

[33] M. Walkinshaw, M.M. Cid, E. Pombo-Villar, unpublished results.

[34] (-)-37: (-)-(IR,4R,6R)-6-[5-(3-Methyl1,2,4-oxadiazol)yl]-2-azabicyclo[2.2.1]heptane hydrogen fumarate salt, m.p. 166$167^{\circ}$ (dec.). $[\alpha]_{\mathrm{D}}^{20}=-41.0(c=0.5, \mathrm{MeOH})$.

[35] (-)-38: (-)-(1R,4R,6R)-2-Methyl-6-[5-(3 methyl-1,2,4-oxadiazol)yl]-2-azabicyclo[2.2.1] heptane hydrogen maleinate, m.p. $163-164^{\circ},[\alpha]_{D}^{20}=-37.8(c=0.55$, $\mathrm{MeOH})$.

[36] (+)-1: (+)-(1R,3R,4R)-3-(3-methyl-1,2,4oxadiazol-5-yl)-1-azabicyclo[2.2.1]heptane, m.p. ca. $50^{\circ},[\alpha]_{\mathrm{D}}^{20}=+92.6(c=1.5$, $\mathrm{CH}_{2} \mathrm{Cl}_{2}$ ); fumarate: m.p. $138=139^{\circ},[\alpha]_{\mathrm{D}}^{20}=$ $+1.07(c=0.46, \mathrm{MeOH}) ; p$-toluenesulfonate: m.p. $143-145^{\circ},[\alpha]_{\mathrm{D}}^{20}=-15.6(c=0.5$, $\left.\mathrm{CH}_{2} \mathrm{Cl}_{2}\right),[14 \mathrm{c}]$ : m.p. $143^{\circ},[\alpha]_{\mathrm{D}}^{20}=-14.8(c$ $=0.5, \mathrm{CH}_{2} \mathrm{Cl}_{2}$ )

[37] J. M. Van Rossum, Arch. Int.Pharmacodyn. $1962,140,592$

[38] a) T.P. Kenakin, Adv. Drug Res. 1986,15, 71; b) R.R. Ruffolo, J. Auton. Pharmacol. $1982,2,277$

[39] a) S.B. Freedman, Br.J. Pharmacol. 1986, 87, 29P; R.M. Eglen, R.L. Whiting, J. Auton. Pharmacol. 1986, 5, 323. b) For examples with serotonergic agonists, see H.W.G.M. Boddeke, A. Fargin, J.R. Raymond, P. Schoefter, D. Hoyer, NaunynSchmiedeberg's Arch. Pharmacol. 1992, $345,257$.

[40] In the oxadiazole series, this hydrophobic interaction is apparently of lesser importance [13b].

[41] J.M. Schulman, M.L. Sabio, R.J. Disch, $J$. Med. Chem. 1983, 26, 817.

[42] The molecular models were built and minimized with SYBYL5.4, Tripos Associates Inc., 1699 S. Hanley Rd., Suite 303, St.Louis, Missouri 63144

[43] J.P. Snyder, Trends Pharmacol. Sci. 1985 , 6,464 .

[44] a) J.M. Schulman, wo Patent 88/07043 (PCT); b) S.B. Freedman, S. Patel, E.A Harley, L.L. Iversen, R. Baker, G.A. Showell, J. Saunders, A. McKnight, N. Newberry, K. Scholey, R. Hargreaves, Eur.J. Pharmacol. 1992, 215, 135; c) G. Lambrecht, U Moser, E. Mutschler, G. Walther, J. Wess, J.Med.Chem. 1986, 29, 1309; d) A. Fischer, R. Brandeis, I. Karton, Z. Pittel, M. Sapir, S. Dachir, A. Levy, E. Heldman, Abstracts, 196th ACS Meeting Los Angeles, Sept. 2530, 1988, Abs. No. MEDI 67; e) G. Schumacher, R. Steinberg, J.P. Kan, J.C Michaud, J.J. Bourgignon, C.G. Wermuth, P. Felz, P. Worms, K. Biziere, Eur. J. Pharmacol. 1989, I66, 139

[45] M.H. Abraham, P.P. Duce, D.V. Prior, D.G.
Barrat, J.J. Morris, P.J. Taylor $J$. Chem. Soc., Perkin Trans. 2 1989, 1355.

[46] a) G. Argay, A. Kalman, P. Perjesi, D. Szabo, Acta Crystallogr., Sect. C 1987, 43, 324; b) M. Hollosi, M. Zewdu, E. Kollat, Z Majer, M. Kajtar, G. Batta, K. Köver, P. Sandor, Int. J. Peptide Protein Res. 1990. 36, 173; c) C.E. Bugg, U. Thewalt, Acta Crystallogr., Sect. B 1975, 31, 121

[47] H. Kooijman, 'Molecular Structures of Muscarinic Agonists and Neuromuscular Blocking Agents', Doctoral Dissertation, Rijksuniversiteit, Utrecht, 1992

[48] I. Langmuir, J. Am. Chem. Soc. 1919, 4I, $868,1543$.

[49] For other examples of the importance and predictive power of Langmuir's original concept for inorganic chemistry see the review: H. Schmidbaur, Fortschr. Chem. Forsch. 1969, 13, 167.

[51] In Goubeau's treatment of isosteres [52] a broad and a narrow definition of isosteres taken from Grimm are cited. Broadly defined isosteres are: compounds which have the same number of atoms and equal numbers of valence electrons. While in the narrow definition the total number of electrons is also conserved. H.G. Grimm, H. Wolff, in 'Handbuch der Physik', Eds. H. Geiger and K. Scheel, Springer Verlag, Berlin, 1933, XXIV, Vol. 2, p. 976,

[52] J. Goubeau, Naturwissenschafien 1948, 35 , 246.

[53] H. Erlenmeyer, Bull. Soc.Chim. Biol. 1948 , 30,792 .

[54] C. Hansch, Intra-Science Rept. 1973, $8,17$.

[55] a) O. Hinsberg, J. Prakt. Chem. 1916, 93 , 302; b) ibid. 1916, 94, 179.

[56] It is interesting to observe that despite the virtually exclusive usage by medicinal chemists of isostere in Erlenmeyer's sense, the definition of the term isostere one finds in the Roche Medical Lexicon 1987 is that of Langmuir.

[57] H.L. Friedman, Symposium on ChemicalBiological Correlation, Natl. Sci. Research Council, publ. No. 206, Washington D.C., 1951, p 295.

[58] To be able to relate opposite biological effects descriptors e.g. positive $((+)$ for agonism or analogous effect) and negative $((-)$ for antagonism or opposite effect) could be assigned to expand the scope of the term bioanalogs. This would be particularly useful for describing bioanalogous groups in a searchable database.

[59] G. Shapiro, P. Floersheim, R. Amstutz, H. Boddeke, G. Bolliger, S. Cottens, A. Enz, G. Gmelin. P. Gull, P. Supavilai, Bioorg. Med. Chem. Lett. 1992, in press.

[60] R.H. Davies, H. Williams, H.J. Smith, in 'Introduction to the principles of drug design', 2nd edn., Ed. H.J. Smith, Butterworth, London, 1988, p. 55.

[61] a) B.Testa, Chirality 1989, I, 7; b) D.J. Triggle, in 'Handbook of Stereoisomers: Drugs in Psychopharmacology', Eds. D.J Triggle and D.R. Triggle, CRC Press, Boca Raton, 1984, pp. 233-430; c) B. Jensen, 'Aspects of the Molecular Structure of Acetylcholine and Related Compounds', FADL's Forlag, Copenhagen, 1984; d) K.M. Williams, Adv' Pharmacol 1991, 22, 57.

[62] B.Testa, in 'Chirality and Biological Activity', Alan R. Liss, New York, 1990, p. 21. 